Illinois State University

ISU ReD: Research and eData

Theses and Dissertations

$4-5-2014$

\title{
Modified Nutrition Facts Panels Help In Identifying Healthier Options
}

Courtney Marie Markey

Illinois State University, cmmarkey11@gmail.com

Follow this and additional works at: https://ir.library.illinoisstate.edu/etd

Part of the Human and Clinical Nutrition Commons

\section{Recommended Citation}

Markey, Courtney Marie, "Modified Nutrition Facts Panels Help In Identifying Healthier Options" (2014). Theses and Dissertations. 175.

https://ir.library.illinoisstate.edu/etd/175

This Thesis is brought to you for free and open access by ISU ReD: Research and eData. It has been accepted for inclusion in Theses and Dissertations by an authorized administrator of ISU ReD: Research and eData. For more information, please contact ISUReD@ilstu.edu. 


\title{
MODIFIED NUTRITION FACTS PANELS HELP IN IDENTIFYING HEALTHIER OPTIONS
}

\author{
Courtney M. Markey
}

72 Pages

August 2014

Background Research shows understanding of information portrayed on nutrition facts panels is low.

Objective Nutrition facts panels were modified to increase identification of healthier label when comparing similar foods.

Design This was study was randomized. Participants, from a Midwestern University, were recruited through email for an online survey.

Participants 738 students responded (4.87\% response rate) and 622 completed the entire survey.

Intervention Participants were randomly assigned one of three variations. One variation was the nutrition facts panel as it is currently used on food labels. Another variation highlighted nutrients on the nutrition facts panel in traffic light colors indicating healthy, moderate, and unhealthy levels. The third variation showed the calorie-containing nutrients in pie graph form, and non-calorie containing nutrients in a bar graph representing percent daily values. Participants were shown a series of two labels within their variation and chose the healthiest one. Participants then answered demographic and nutrition related questions. 
Main outcome measures Choosing the healthier label meant a correct response. Eight pairs of labels were shown, therefore there were eight possible correct answers. Statistical analyses Independent samples t-Tests were performed to analyze differences in correct responses for modified label variations and the Current label and to identify differences between genders. One-Way ANOVA compared number of correct answers to demographic data. Linear regression analyzed relationships between age and frequency of label use.

Results The graph and traffic light variations had significantly more correct answers than the control $(\mathrm{p}=0.00)$. Differences in demographic information were found in the Current label variation, not in either modified label variation.

Conclusions Modified nutrition facts panels helped participants identify healthier labels more often. No one demographic characteristic increased the likelihood of picking the healthier label in either modified variation. This is important, as the Food and Drug Administration has proposed changes to enhance understanding of food labels. 
MODIFIED NUTRITION FACTS PANELS HELP IN IDENTIFYING HEALTHIER OPTIONS

COURTNEY M. MARKEY

A Thesis Submitted in Partial Fulfillment of the Requirements for the Degree of

MASTER OF SCIENCES

Department of Family and Consumer Science

ILLINOIS STATE UNIVERSITY 
MODIFIED NUTRITION FACTS PANELS HELP IN IDENTIFYING HEALTHIER OPTIONS

COURTNEY M. MARKEY

COMMITTEE MEMBERS:

Jan Murphy, Chair

Kevin Pietro

Yoon Jin Ma

Julie Schumacher 


\section{ACKNOWLEDGMENTS}

I would like to thank my committee members, Jan Murphy, Kevin Pietro, Yoon Jin Ma, and Julie Schumacher for your help and guidance through this process. A special thanks goes to Kevin who provided the initial idea for this topic and encouraged me to pursue this research. This thesis is dedicated to my family Nancy, Jeff, and Aaron who supported me, provided positive feedback, and helped me focus on the end result.

C.M.M. 


\section{CONTENTS}

\section{Page}

ACKNOWLEDGMENTS

CONTENTS

TABLES iv

CHAPTER

\section{MODIFIED NUTRITION FACTS PANELS HELP IN IDENTIFYING} HEALTHIER OPTIONS 1

Introduction 1

Hypotheses $\quad 5$

$\begin{array}{lr}\text { Methods } & 7\end{array}$

$\begin{array}{ll}\text { Results } & 10\end{array}$

Hypothesis $1 \quad 16$

Hypothesis 2

Hypothesis $3 \quad 17$

Hypothesis $4 \quad 18$

Hypothesis 5

Hypothesis $6 \quad 19$

Hypothesis $7 \quad 20$

$\begin{array}{ll}\text { Discussion } & 20\end{array}$

Conclusion 24

References 25

II. REVIEW OF RELATED LITERATURE 28

Introduction $\quad 28$

Nutrient Level Recommendations $\quad 29$

Demographics of Food Label Users $\quad 32$

Diets of Food Label Users $\quad 33$ 
Barriers to Label Use

Proposed Changes to Current Food Labels

Front-of-Package Labeling

Traffic Light Labeling System

How to Correctly Use Pie Graphs

References

APPENDIX A: $\quad$ Email Sent to Students

APPENDIX B: Informed Consent

APPENDIX C: $\quad$ Survey Label Pairs

APPENDIX D: $\quad$ Demographic and Nutrition Questions 


\section{TABLES}

Table $\quad$ Page

1. Traffic Light Label Color Distinctions $\quad 12$

2. Characteristics and Demographics 13

3. Correct Label Score Related to Label Variation, Gender, and Age 14

4. Ethnicity Related to Correct Label Choices 15

5. Year in School Related to Correct Label Choices 16 


\section{CHAPTER I}

\section{MODIFIED NUTRITION FACTS PANELS HELP IN IDENTIFYING HEALTHIER}

\section{OPTIONS}

\section{Introduction}

Since 1994, standard nutrition facts panels (NFPs) have been present on most packaged foods. The NFP, a tool developed for the health of the consumer, contains information such as nutrient content, serving size, kilocalories and percent daily values in the food described ("Inspections, compliance," 1995). The Nutrition Labeling and Education Act of 1990 developed the current label format. This act dictates what font, font size, and units all nutrient articles on the label are to be measured in. It was hoped that consumers would use this tool at the point of purchase to increase healthy food selections, resulting in reduction of certain chronic diseases ("A Food Labeling Guide," 1994). Unfortunately, it has been a dismal failure as a method of weight control. Obesity has continued to rise at an alarming rate since the implementation of the Nutrition Labeling and Education Act.

From 1990 to 2010, the Center for Disease Control released annual state obesity rate statistics, which clearly illustrated America's challenges with weight control. For example, in 1990, the prevalence of obesity was less than ten percent in ten states. No state reported an obesity rate over 15 percent. Obesity is defined as having a Body Mass 
Index greater than $30 \mathrm{~kg} / \mathrm{m}^{2}$. Twenty years later, in 2010 , zero states reported obesity rates less than ten percent. Instead, over one-third of the states reported obesity rates greater than or equal to twenty-five percent (“Obesity Trends," 2013). In 2012, almost 35\% of those over the age of 20 were obese (Ogden, Carroll, Kit, \& Flegal, 2014). Furthermore, this number does not include those who are simply overweight. It is clear that obesity has become a serious issue. From this data, it can be concluded that the NFP may not be adequately functioning as the tool it was created to be.

Connected to the rise of obesity rates is the prevalence of different diseases. Those diseases most related to obesity are cardiovascular disease, type II diabetes, and certain cancers $(\mathrm{Hu}, 2003)$. The Center for Disease Control last estimated the cost of treating and managing obesity related diseases to be around 147 billion dollars in 2008 (Finkelstein, Trogdon, Cohen, \& Dietz, 2009). Many studies have found diets high in fruits, vegetables and fiber and low in saturated fats, trans fats, salt, and added sugars reduce the risk of becoming obese and developing diseases (Kromhout, Menitti, Hugo, \& Sans, 2002). A healthier diet is significantly more cost effective than treatment of disease. By utilizing information on the NFP, consumers should be able to identify foods that help prevent obesity and its related diseases.

Researchers have inquired about the types of people who choose to use the NFP and how their diets are affected. Multiple studies found that those who declare use of the NFP tend to be women, have reached an education level past high school, have moderate to high incomes, and have a belief that a healthy diet prevents disease. The people who use the NFP most often were also found to consume healthier diets than those who did not use them. "Healthier diets" included increased fruits, vegetables, and fiber and a 
reduced consumption of fat, saturated fat, kilocalories, sugar, sodium, and cholesterol (Neuhouser, Kristal, \& Patterson, 1999; Ollberding, Wolf, \& Contento, 2011; Satia, Galanko, \& Neuhouser, 2005). It is important to note that when a NFP is used, there are health benefits.

However, many consumers do not utilize the information provided to them. One reason is that NFP labels are confusing and hard to comprehend because of the abundance of information provided (Wills, Schmidt, Pillo-Blocka, \& Cairns, 2009). A Food and Drug Administration subcommittee, the Obesity Working Group, determined that many consumers were confused by the percent daily values or did not believe the 2000-calorie diet pertained to them (Obesity Working Group, 2004). Another barrier to successful use of nutrition labels is that people with low incomes, especially those enrolled in food assistance programs, tend to be less educated. They therefore, have a greater chance of not having the knowledge needed to properly read the NFP and may not understand how the NFP can assist in developing a healthy diet for disease management (Perez-Escamilla \& Haldeman, 2002). Modifications to the NFP that make them easier and less time consuming to comprehend could help this population make more wholesome and informed food purchases.

Recently, the Food and Drug Administration released proposed changes to NFPs. This will be the first time in twenty years that modifications have been made to food labels, besides the addition of trans fat in 2006. Positive changes to the labels will include the addition of more nutrients such as vitamin D and potassium, stronger standards for serving sizes, and a larger and bolder display of calorie content. The percent daily values will also be updated to reflect more current nutrient recommendations made 
by the Institute of Medicine and Daily Guidelines for Americans. Although the FDA's research continues to show that consumers do not completely comprehend how to use percent daily values, the Food and Drug Administration has proposed to place them in front of nutrient listings, in order to make them more prominent ("Food Labeling: Revision,”2014).

Other countries such as those within the European Union, Australia, and New Zealand have also researched how to best present nutrient information to those with limited nutrition education (Cowburn \& Stockly, 2004; White, Thomson \& Signal, 2010). Most have supported front-of-pack labeling efforts (FOP) where a few key nutrients are presented in different formats. Borgmeier and Westenhoefer (2009) detail a few of the most popular formats for FOP labels. One format is the traffic light system that determines high, medium, and low levels of a nutrient and displays them in green, amber, or red respectively. Another displays a percentage of the nutrient compared to what is recommended in one's daily diet. A different format summarizes all the nutrients together as a score or a checkmark that is presented on the front of the package (Borgmeier \& Westenhoefer, 2009). With so many variations, consumers can become confused about what is actually the healthy choice.

Although proposed changes to the NFP have been made, these changes may not be enough to help consumers quickly and completely understand the information being conveyed. The FDA is still relying on the consumer's ability to interpret percent daily values; despite research that has proven this ineffective (Obesity Working Group, 2004). Many studies have researched different front-of-pack labeling efforts and their affects on food choices, but very few have modified the NFP to increase healthy food choices. 
Modifications to NFPs should be focused on simplification; to prevent time spent analyzing numbers on the package. Modifications should also ensure that those of all demographics are able understand the label, not just those who use it most often. The aim of this study was to create two different NFPs that participants could understand better than the current NFP. NFPs were modified using colors and graphs to determine if these changes would increase identification of the healthier option when comparing two similar foods. Demographic information was also collected to identify any differences in healthy label choices.

\section{Hypotheses}

The hypotheses tested in this study include:

1. Traffic light based nutrition facts panels will increase number of correct choices when compared to the current nutrition facts panel.

2. Graph based nutrition facts panels will increase number of correct choices when compared to the current nutrition facts panel.

3. Participant's gender will affect the number of correct label choices.

a. Females will choose the correct label more often than males when using current labels.

b. There will be no difference in correct label choice by gender when using traffic light based labels.

c. There will be no difference in correct label choice by gender when using graph based labels.

4. Age will affect number of correct label choices. 
a. As age increases, number of correct label choices will increase when using current labels.

b. Age will not affect correct label choices when using traffic light based labels.

c. Age will not affect correct label choices when using graph based labels.

5. Participant's ethnicity will not affect number of correct label choices.

a. Participant's ethnicity will not affect number of correct label choices when using current labels.

b. Participant's ethnicity will not affect number of correct label choices when using traffic light based labels.

c. Participant's ethnicity will not affect number of correct label choices using graph based labels.

6. Year in school will affect number of correct label choices.

a. The further along in school a participant is, the greater number of correct label choices they will make when using current labels.

b. Year in school will not affect correct label choices when using traffic light based labels.

c. Year in school will not affect correct label choices when using graph based labels.

7. Increased use of nutrition labels by a participant will affect the number of correct label choices.

a. Increased use of nutrition labels will increase the number of correct label choices when using current labels. 
b. Increased use of nutrition labels will have no effect on number of correct label choices when using the traffic light based labels.

c. Increased use of nutrition labels will have no effect on number of correct label choices when using the graph based labels.

\section{Methods}

Students at a large Midwestern university made up the sample for this study. Any student that had agreed to receive surveys through email was sent information about the study and a link to one of three online surveys. Two weeks later, a follow up email was sent to the same participants containing the same link they had originally received. The survey was open for a total of four weeks. This study was an experimental, randomized design. The link to one of the three surveys was sent randomly through email. After following the survey link provided in the email, participants were provided with the informed consent. Agreeing to the informed consent and verification that they were at least 18 years of age then took participants to the survey.

Study design was influenced by two different studies. The first showed different food label formats and asked participants to answer questions about nutrition (Borgmeier et al., 2009). The second study labeled food items in a cafeteria with red, yellow, and green stickers based on food's healthfulness (Thorndike, Sonneberg, Riis, Barraclough, \& Levy, 2012). In this study, two nutrition facts panels were shown, side-by-side, of similar but different foods. Participants were asked to decide which picture they believed to be the healthier food, based only on information in the nutrition facts panel and an indication as to the type of food pictured. The first pair of food labels was used as an example; participants chose the picture they thought was healthiest. Answers for the example page 
were not recorded. The following eight pages of the survey showed the participant pairs of food using the same labeling variation as the example; the label chosen by participants was recorded. Participants were required to choose an answer before proceeding to the next page, and could not go back to change answers. Demographic and nutrition related questions were asked at the end of each survey. After completing the survey, participants were able to follow a link to enter into a drawing to win one of ten $\$ 10$ gift cards to a local restaurant near campus.

All questions in this survey were original. Pictures of labels used were not identifiable to the original food package. The three surveys were created using SelectSurvey.NETv4.081.000 (Copyright 2012). Each survey consisted of one of three different label variations: Graph based labels, Traffic light based labels, or Current labels. Nutrition facts panels in the Current label variation were pictured exactly how they are on the package. The Graph variation pictured macronutrient calorie make up (fat, saturated fat, trans fat, carbohydrate, sugar, and protein) in a pie chart. Other nutrients (cholesterol, sodium, potassium fiber, vitamin A, vitamin C, calcium, and iron) were pictured in a bar graph based on their percent daily values. Graphs were created using Microsoft Excel (2004 for Mac Version 11.6.6). For the Traffic Light variation, control pictures were formatted to a grayscale and calories, total fat, saturated fat, trans fat, cholesterol, sodium, fiber, and sugar were highlighted either green, yellow, or red. Healthy nutrient levels were represented in green, moderate levels in yellow, and unhealthy levels in red (Table 1). The colors were chosen to be reminiscent of a traffic light. The Dietary Guidelines for Americans (2010), Dietary Reference Intakes 
("Dietary Reference Intakes for energy," 2005; "Dietary Reference Intakes for water," 2005), recommendations by the American Heart Association (2011), and the Food and Drug Administration (“Sodium in your Diet," 2013) were used to create the color distinctions for all nutrients. Traffic light labels were created on a tablet using the Color Effects application (version 5.53 created by The Othernet LLC). Food items were chosen for this study based on an article by Dove (2011) which provided the most popular food items purchased at the grocery store. Carbonated beverages and jelly were included on the list by Dove, but because of these item's lack of nutrients, they were not included in this study. Butter and juice were substituted for these items instead. Foods within each label pair were on opposite ends of the health spectrum. By looking at the entire food package, many could have easily identified the healthier food. Nutrition facts panels used in this study were from: $100 \%$ juice and juice cocktail of the same flavor, a whole wheat high fiber cereal and a sugary children's cereal, frozen dinners of the same dish from a brand known for healthier meals and another known for home style meals, baked plain chips and flavored regular chips, $100 \%$ natural peanut butter and peanut butter with added honey, $100 \%$ no additive turkey deli meat and turkey deli meat with added meat parts, $100 \%$ whole wheat, higher fiber, low sodium bread and white bread, and regular butter and butter spread. Demographic questions such as age, sex, ethnicity, and year in school, and frequency of label use were included in the survey.

Statistical analysis was performed using Statistical Package for the Social Sciences (SPSS). A variable was computed that summed the number of correct "healthier choice" answers. This score could range from zero to eight correct. Independent samples t-tests were used to analyze the significance $(\mathrm{p}<0.05)$ of the relationships between correct 
answers of the current label variation to each of the scores for modified label variations (H1\&2). An independent samples t-test was also used to analyze significant relationships between genders within each label variation (H3a-c). Linear regression was used to determine any significant relationship between age and correct label choice for each label variation (H4a-c). One way-ANOVA was used to analyze significant relationships between ethnicities within each label variation (H5 a-c). One way-ANOVA was used to analyze any significant relationships between correct label choice and year in school within each label variation (H6a-c). Linear regression was used to identify any significant relationship between number of correct label choices and how often the participant uses food labels (H7a-c). Frequency of label use was measured on a five point Likert scale ranging from never to always.

Statistical analyses were conducted to ensure randomization of label variations. Chi-square analysis was used to compare label variation to frequency of label use. No statistically significant relationships were found, therefore, randomization can be assumed. One way-ANOVA was also used to confirm randomization of label variations to age, ethnicity and year in school. No significant relationships were found, so randomization may be assumed. Chi-square analysis was used to confirm randomization of label variations for gender. No statistically significant relationships were found. Hence, it can be assumed that participant's gender was random within label variations.

\section{Results}

Out of 19,924 students, 15,162 elected to have surveys sent to them. Each survey condition was sent to one third of these students, 5,054 recipients. Out of these recipients, 738 students began one of the three surveys and 622 completed an entire survey. 
According to the Planning Research and Policy Analysis (2013) for the University, females account for $55.9 \%$ of the university's population, and minorities make up $18.2 \%$ of the student body. Year in school breakdown for the University is as follows: freshmen $21 \%$, sophomores $17 \%$, juniors $23 \%$, seniors $28 \%$, and graduate students $11 \%$. All three label variations were primarily completed by seniors and graduate students as well as a 9$12 \%$ more females than the University make up and slightly fewer minority participants. Therefore this sample does not exactly represent the University's demographic make up (See Table 2).

The Current label variation had 208 (33.4\%) participants, 138 (66\%) participants were female, and $45(21 \%)$ were minorities. Mean age for this variation was 23.8 years old $(s d=7.71)$. The Graph label variation had 195 (31.3\%) participants, $125(64 \%)$ were female, and $28(14 \%)$ were minorities. Mean age was 24.3 years old $(s d=6.91)$. The Traffic light label variation had 219 (35.2\%) participants, 147 (67\%) were female, and 24 $(11 \%)$ minorities. The average age in this variation was 23.5 years old $(s d=6.92)$. 
Table 1. Traffic Light Label Distinctions

\section{Red Label}

Kilocalories Entrees $>700 \mathrm{kcal}$,

Food items $>200 \mathrm{kcal}$,

Beverages/condiments

$>100 \mathrm{kcal}$

Total Fat

$50 \%$ or more

kilocalories from fat

Saturated $\quad 10 \%$ kilocalories or

Fat

Trans Fat All trans fats

Cholesterol >300 mg cholesterol per 2000 kilocalories

$>11$ grams sugar

Entree or food item $>480 \mathrm{mg}$ sodium Beverage $>100 \mathrm{mg}$ sodium

\section{Yellow Label}

Entrees 400-700kcal,

Food items 100-200,

Beverages/condiments

50-100

$31-49 \%$ kilocalories

from fat

9-8\% kilocalories

from saturated fat

200-300 mg

cholesterol per 200

kilocalories

8-11 grams sugar

Entree or food item 120-480 mg sodium, Beverage 1-100 mg sodium

\section{Green Label}

Entree $<400 \mathrm{kcal}$, Food item $<100 \mathrm{kcal}$, Beverages/condiments $<$ kcal 50

$30 \%$ or less

kilocalories from fat

$7 \%$ or less

kilocalories from saturated fat

$<200 \mathrm{mg}$ cholesterol

or less per 2000

kilocalories

$<$ 7grams sugar

Green- Entree or food item $<120 \mathrm{mg}$ sodium, Beverage 0mg sodium

$>7 \mathrm{~g}$ fiber per 1000 kcal 
Table 2. Characteristics and Demographics

\begin{tabular}{|c|c|c|c|c|}
\hline $\begin{array}{r}\text { Label } \\
\text { Variation } \\
\mathbf{n}(\%)\end{array}$ & $\begin{array}{l}\text { Current label } \\
208(33.4)\end{array}$ & $\begin{array}{l}\text { Graph Label } \\
195(31.3)\end{array}$ & $\begin{array}{l}\text { Traffic Light } \\
\text { Label } 219(35.2)\end{array}$ & $\begin{array}{l}\text { Student } \\
\text { Population } \\
19,924\end{array}$ \\
\hline \multicolumn{5}{|l|}{ Gender n (\%) } \\
\hline Female & $138(66)$ & $125(64)$ & 147 (67) & $11,137(55.9)$ \\
\hline Male & $69(33)$ & $70(36)$ & $72(33)$ & $8787(44.1)$ \\
\hline \multicolumn{5}{|l|}{$\begin{array}{r}\text { Ethnicity n } \\
(\%)\end{array}$} \\
\hline Native Am & $2(.96)$ & $1(0.51)$ & $0(0)$ & \\
\hline Asian & $11(5.29)$ & $5(2.56)$ & $6(2.74)$ & \\
\hline \multicolumn{5}{|l|}{ Black/African } \\
\hline $\mathrm{Am}$ & $16(7.69)$ & $10(5.13)$ & 7 (3.19) & \\
\hline White & $163(78.4)$ & $167(85.6)$ & $195(89.0)$ & $16,297(81.8)$ \\
\hline \multicolumn{5}{|l|}{ Hispanic/Latin } \\
\hline o & $13(6.25)$ & $11(5.64)$ & $8(3.65)$ & \\
\hline Other & $3(1.44)$ & $1(0.51)$ & $3(1.37)$ & \\
\hline \multicolumn{5}{|l|}{$\begin{array}{l}\text { Education } \\
\text { level n (\%) }\end{array}$} \\
\hline Freshman & $32(15.4)$ & $17(8.72)$ & $22(10.0)$ & $4,184(21)$ \\
\hline Sophomore & $26(12.5)$ & $26(13.3)$ & $31(14.2)$ & 3,387 (17) \\
\hline Junior & $48(23.1)$ & $40(20.5)$ & $52(23.7)$ & $4,583(23)$ \\
\hline Senior & $50(24.0)$ & $51(26.2)$ & $59(26.9)$ & $5,579(28)$ \\
\hline Graduate & $51(24.5)$ & $61(31.3)$ & $53(24.2)$ & $2,192(11)$ \\
\hline $\begin{array}{r}\text { Age }(\text { years }), \\
\text { mean }(S D)\end{array}$ & $23.8(7.71)$ & $24.3(6.91)$ & $23.5(6.92)$ & \\
\hline
\end{tabular}


Table 3. Correct Label Score Related to Label Variation, Gender, and Age

\begin{tabular}{|c|c|c|c|c|c|}
\hline & $M$ & $S D$ & $\mathbf{t}$ & df & $P$-value \\
\hline \multicolumn{6}{|l|}{ Label Variation $(\mathbf{n})^{\mathbf{a}}$} \\
\hline Current (208) & 6.06 & 1.16 & & & \\
\hline Graph (195) & 6.52 & 1.004 & -3.71 & 389.73 & $0.00 * * *$ \\
\hline Traffic light (219) & 6.57 & 1.294 & -4.84 & 425 & $0.00 * * *$ \\
\hline \multicolumn{6}{|l|}{ Gender $^{\mathrm{a}}$} \\
\hline Current & & & -2.43 & 205 & $.016 *$ \\
\hline Female (138) & 5.92 & 1.16 & & & \\
\hline Male (69) & 6.33 & 1.13 & & & \\
\hline Graph & & & 0.72 & 193 & 0.472 \\
\hline Female (125) & 6.57 & 1.27 & & & \\
\hline Male (70) & 6.43 & 1.35 & & & \\
\hline Traffic light & & & -1.57 & 217 & 0.118 \\
\hline Female (147) & 6.50 & 0.989 & & & \\
\hline Male (70) & 6.72 & 1.02 & & & \\
\hline Age $^{b}$ & $\mathbf{R}\left(\mathbf{R}^{2)}\right.$ & $\boldsymbol{\beta}$ & $\mathbf{t}$ & $\mathbf{F}$ & \\
\hline Current & $.200(0.04)$ & .200 & 2.94 & 8.62 & $.004 * *$ \\
\hline Graph & $.135(.018)$ & 0.135 & 1.89 & 3.59 & 0.06 \\
\hline Traffic light & $.045(.002)$ & 0.045 & .658 & 0.66 & 0.511 \\
\hline \multicolumn{6}{|l|}{ Frequency of Label Use ${ }^{b}$} \\
\hline Current & $.003(.055)$ & .055 & .786 & .619 & .432 \\
\hline Graph & $.053(.231)$ & .231 & 3.30 & 10.9 & $.001 * *$ \\
\hline Traffic light & $.002(.048)$ & .048 & .706 & .498 & .481 \\
\hline \multicolumn{6}{|c|}{$\begin{array}{l}\text { a Differences between label variations and gender were analyzed by Independent } \mathrm{t} \text {-test } \\
\mathrm{b} \text { Relationships between age and score, and frequency of label use and score were analyzed by Linear Regression } \\
\text { *significant at } P<.05 \\
* * \text { significant at } P<.01 \\
* * * \text { significant at } P<.001\end{array}$} \\
\hline
\end{tabular}


Table 4. Ethnicity Related to Correct Label Choices

\begin{tabular}{lccrr}
\hline $\begin{array}{l}\text { Ethnicity } \\
\text { Current }\end{array}$ & $\boldsymbol{M}$ & $\boldsymbol{S D}$ & $\begin{array}{r}\text { F } \\
\mathbf{2 . 3 2}\end{array}$ & $\begin{array}{r}\boldsymbol{P} \text {-value } \\
\mathbf{. 0 4 5}\end{array}$ \\
Native American (2) & 4.00 & 0.00 & & \\
Asian (11) & 6.00 & .775 & & \\
Black/African Am & & & & \\
(16) & 5.81 & 1.28 & & \\
White (163) & 6.07 & 1.16 & & \\
Hispanic/Latino (13) & 6.31 & 1.11 & & \\
Other (3) & 7.33 & .577 & $\mathbf{. 0 6 9}$ \\
Graph & & & $\mathbf{2 . 0 9}$ & \\
Native American (1) & 4.00 & & & \\
Asian (5) & 5.40 & 1.14 & & \\
Black/African Am(10) & 6.30 & .675 & & \\
White (167) & 6.54 & 1.31 & & \\
Hispanic/Latino (11) & 7.09 & 1.22 & & \\
Other (1) & 7.00 & & & \\
Traffic light & & & $\mathbf{. 5 7 5}$ \\
Asian (6) & 6.67 & .816 & & \\
Black/ African Am (7) & 7.00 & .816 & & \\
White (195) & 6.57 & 1.02 & & \\
Hispanic/Latino (8) & 6.25 & 1.04 & & \\
Other (3) & 6.33 & .577 & & \\
${ }^{2}$ Differences in year in ethnicity and correct label choices analyzed by One Way-ANOVA & \\
${ }^{*}$ significant at $P<.05$ & & &
\end{tabular}


Table 5. Year in School Related to Correct Label Choices

\begin{tabular}{lccrc}
\hline $\begin{array}{l}\text { Year in School }{ }^{\text {a }} \text { (n) } \\
\text { Current }\end{array}$ & $\boldsymbol{M}$ & $\boldsymbol{S D}$ & $\begin{array}{r}\text { F } \\
\mathbf{4 . 4 7}\end{array}$ & $\begin{array}{r}\boldsymbol{P} \text {-value } \\
\mathbf{0 . 0 0 2} * *\end{array}$ \\
Freshmen (32) & 5.44 & 1.19 & & \\
Sophomore (26) & 0.96 & 0.99 & & \\
Junior (48) & 5.94 & 1.25 & & \\
Senior (50) & 6.24 & 1.24 & & $\mathbf{0 . 7 1 2}$ \\
Graduate (51) & 6.45 & 0.901 & & \\
Graph & & & $\mathbf{0 . 5 3 3}$ & \\
Freshmen (17) & 6.47 & 1.28 & & \\
Sophomore (26) & 6.43 & 1.36 & & $\mathbf{0 . 3 8}$ \\
Junior (40) & 6.35 & 1.35 & & \\
Senior (51) & 6.73 & 1.13 & & \\
Graduate (61) & 6.51 & 1.37 & & \\
Traffic light & & & & \\
Freshmen (22) & 6.77 & 0.75 & & \\
Sophomore (31) & 6.35 & 0.99 & & \\
Junior (52) & 6.42 & 1.05 & & \\
Senior (59) & 6.63 & 1.11 & & \\
Graduate (53) & 6.68 & 0.936 & & \\
${ }^{a}$ Differences in year in school and correct label choices analyzed by One Way-ANOVA & \\
**significant at $P<.01$ & & & & \\
& & & & \\
& & & & \\
\end{tabular}

\section{Hypothesis 1}

H1. The mean score for correct answers in the Traffic light label variation $(M=6.57, S D=1.00)$ is significantly higher than the mean score in the Current label variation $(M=6.06, S D=1.163)$ at the .05 level $(\mathrm{t}=-4.84, \mathrm{df}=425, P=.000)$. Thus, $\mathrm{H} 1$ is statistically supported (Table 3). Based on Levene's Test, the variances were significantly different, so a t-test that did assume equality of variances was conducted.

\section{Hypothesis 2}

H2. The mean score for correct answers in the Graph Label variation $(M=6.53$, $S D=1.29)$ is significantly higher than the mean scores for the Current label variation $(M=6.06, S D=1.163)$ at the .05 level $(\mathrm{t}=-3.71, \mathrm{df}=389.732, P=.000)$. Therefore, $\mathrm{H} 2$ is statistically supported (Table 3). Based on Levene's Test, the variances were not 
significantly different. Therefore, a t-test that did not assume equality of variances was conducted.

\section{Hypothesis 3}

$\mathrm{H} 3 \mathrm{a}$. The score for correct answers for males in the Current label variation $(M=6.33, S D=1.13)$ is significantly higher than the score for correct answers for females in the same label variation $(M=5.92, S D=1.16)$ at the .05 level $(\mathrm{t}=-2.43$, $\mathrm{df}=205$, $P=.016)$. It was hypothesized that female's scores would be higher; therefore H3a is not statistically supported (Table 3). Based on Levene's Test, the variances were significantly different. Therefore, a t-test that did assume equality of variances was conducted. This finding could be influenced by gender differences within this label variation. While females make up 55\% of the student population at this University, females made up $66 \%$ of the sample in the Current label variation.

H3b. The scores for males $(M=6.43, S D=1.38)$ and females $(M=6.57$, $S D=1.27$ ) in the Graph label variation were not found to be significantly different at the .05 level $(\mathrm{t}=.721, \mathrm{df}=193, P=.472)$. Thus, $\mathrm{H} 3 \mathrm{~b}$ is statistically supported (Table 3$)$. Based on Levene's Test, the variances were significantly different. Therefore, a t-test that did assume equality of variances was conducted.

H3c. Scores for males $(M=6.72, S D=1.02)$ and females $(M=6.50, S D=.989)$ were not found to be significantly different in the Traffic light label variation $(t=-1.57$, $\mathrm{df}=217, P=.118$ ). From this data, H3c is statistically supported (Table 3 ). Based on Levene's Test, the variances were significantly different. Therefore, a t-test that did assume equality of variances was conducted. 


\section{Hypothesis 4}

$\mathrm{H} 4 \mathrm{a}$. Age explained a significant portion of the variance in exam score $\left(\mathrm{R}^{2}=.04\right.$, $\mathrm{F}(1,206)=8.62, P=.004)$. Age also significantly predicted score for correct label choices for the Current label variation $(\beta=.200, \mathrm{t}(207)=2.94, P=.004)$. For every oneyear increase in age, we can expect a corresponding .20 increase in correct label choices for the current label variation. Here, H4a is statistically supported (Table 3).

H4b. There was no relationship between score for correct label choices and age in the Graph label variation $\left(\mathrm{R}^{2}=.018, \mathrm{~F}(1,193)=3.89, P 6\right)(\beta=.135, \mathrm{t}(194)=1.89$, $P=.06$ ). From this data, $\mathrm{H} 4 \mathrm{~b}$ can be statistically supported (Table 3 ).

H4c. No relationship was found between score for correct label choices and age in the Traffic light label variation $\left(\mathrm{R}^{2}=.002, \mathrm{~F}(1,217)=.433, P=.511\right)(\beta=.045, \mathrm{t}(218)$ $=.658, P=.511) . \mathrm{H} 4 \mathrm{c}$ is statistically supported (Table 3$)$.

\section{Hypothesis 5}

H5a. Score for correct label choice was compared to participant's ethnicity. The mean differences among groups are statistically significant at the .05 level $(F(5,202)=$ $2.32, P=.045)$. In the Current label group, a significant difference in scores was found between the Native American $(M=4.00, S D=.000)$ and Other $(M=7.33, S D=.557)$ ethnicities. Therefore, H5a is not statistically supported (Table 4). Because a test for homogeneity of variances assumed equal variances and the sample sizes were different, a Hochberg's post hoc test was conducted which confirmed the significance found $(P=.025)$.

H5b. No difference between score for correct label choice and ethnicity was found in the Graph label variation $(\mathrm{F}(5,189)=2.086, P=.069)$. Here, H5b is statistically 
supported (Table 4).

H5c. No difference between score for correct label choice and ethnicity was found in the Traffic Light label variation $(\mathrm{F}(4,214)=.575, P=.681)$. Thus, H5c is statistically supported (Table 4).

\section{Hypothesis 6}

H6a. The differences among means between year in school and correct label score are statistically significant at the .05 level $(\mathrm{F}(4,202)=4.471, \mathrm{P}=.002)$. A difference in scores for correct label choice was noted between freshmen $(M=5.44, S D=1.19)$ and seniors $(M=6.24, S D=1.24)$, and freshmen and graduate students $(M=6.45, S D=.901)$ within the Current label variation. From this information, it can be assumed the H6a is statistically supported (Table 5). A test for homogeneity of variances assumed equal variances and sample sizes were different; therefore a Hochberg's pot hoc was conducted. From this analysis, it was determined that the difference in scores between freshmen and seniors $(P=.019)$ and freshmen and graduate students $(P=.001)$ was significant.

H6b. No statistically significant differences were found between year in school and score for correct label choices in the Graph label variation $(\mathrm{F}(4,190)=.533$, $P=.712$ ). Thus, H6b is statistically supported (Table 5).

H6c. No statistically significant differences were found between year in school and score for correct label choices in the Traffic light label variation $(F(4,212)=1.06$, $P=.379$ ). This data statistically supports H6c (Table 5). 


\section{Hypothesis 7}

H7a. Frequency of label use was not a predictor of score for correct label choices in the Current label variation $\left(\mathrm{R}^{2}=.003, \mathrm{~F}(1,206)=.619 P=.432\right)(\beta=.055, \mathrm{t}(207)=$ $.786, P=.432$ ). This data does not statistically support $\mathrm{H} 7$ a (Table 3 ).

H7b. Increased label use explained a significant portion of the variance in correct label score $\left(\mathrm{R}^{2}=.053, \mathrm{~F}(1,193)=10.9, \mathrm{P}=.001\right)$. Frequency of label use was also a predictor of score for correct label choices in the Graph label variation $(\beta=.231, \mathrm{t}(194)$ $=3.30, P=.001)$. For every unit increase in frequency of label use, we expect a corresponding .231 standard deviation increase in score for correct label choice. Therefore, H7b was not statistically supported (Table 3).

H7c. Frequency of label use was not a predictor of score for correct label choices in the Traffic light label variation $\left(\mathrm{R}^{2}=.002, \mathrm{~F}(1,217)=.498, P=.481\right)(\beta=.048, \mathrm{t}$ $(218)=.706, P=.481)$. Thus, $\mathrm{H} 7 \mathrm{c}$ is statistically supported (Table 3 ).

\section{Discussion}

Research shows that consumers often choose not use NFPs because of lack of understanding and time to comprehend them (Wills et al., 2009; Cowburn et al., 2004; Fuenekes, Gortemaker, Willems, Lion, \& van den Kommer, 2008). While reviewing the literature, many suggestions for front of pack labeling were found to help improve consumer understanding (Childs, 2012; Hersey, Wohlgenant, Arsenault, Kosa, \& Muth, 2013). But, few studies made modifications to the NFP for improved comprehension. The FDA has proposed changes to NFP, which are a step in the right direction. Some positive improvements include alterations to serving sizes, how calories are displayed, and additions of vitamin $\mathrm{D}$ and potassium levels. Unfortunately, changes are not drastic 
enough to increase understanding of specific nutrient levels and percent daily values ("Food Labeling: Revision," 2014). Findings from this present study show that modified nutrition labels can help in identifying healthier foods when comparing two similar food items. In fact, participants in both modified label variations chose the healthier option more often than those in the Current label variation.

Modifications to NFPs must ensure that all demographics and education levels are equally able comprehend the information conveyed. Research has shown that those who currently do not use labels tend to be from lower income groups, are less likely to have an education past high school, and had little exposure to nutrition education (PerezEscamilla et al., 2002). In this present study, significant differences between demographics and education levels did not occur in both modified nutrition label variations.

In the Current label variation, males on average chose the healthier label more often than females. This was an interesting finding because previous research shows that women utilize food label more often than men (Ollberding et al., 2011). Therefore, it was assumed females would have the higher score. In both the Graph and Traffic light label variations, differences between genders did not occur.

Research has found that older age groups tend to use nutrition labels more often when compared to younger age groups (Todd \& Variyam, 2008). This statement may be supported by data from this study. Older participants were more likely to choose the correct label in the Current label variation than younger participants. The age factor was eliminated in both of the modified nutrition labels.

Previous studies suggests that those with higher education attainment tend to use 
nutrition labels most often (Ollberding et al., 2011; Satia, et al., 2005; Neuhouser, et al., 1999). Even though students at a University will all have similar education backgrounds, this study continued to support this data. A difference of only three to four years of extra education increased healthy label choices for the Current label variation. Both of the modified versions of NFPs eliminated this bias; increased education did not increase number of correct label choices for these modified variations. Although, this finding could have been related to age because most seniors and graduate students tend to be older than freshmen.

Most ethnicity differences found in label use are related to income and education level (Perez-Escamilla et al., 2002). Because those attending Universities have similar education backgrounds, no differences in ethnicity were expected for any label variation. The current label variation did have a significant difference between the Native American and Other ethnicities. One possible explanation for this outcome is the very small sample in each of these categories. There were two participants in the Native American group and only three in the Other group. No differences where found in either of the modified label groups. The overall goal of this study, to create modified NFPs that increased ability to choose the healthier item, was accomplished. In addition, both modified nutrition labels eliminated the differences between genders, age, education level, and ethnicities that occurred in the Current label.

It was hypothesized that the more frequently a participant used food labels in their everyday life, the better they would be at identifying the healthier label in the Current label variation. This was solely based on the inference that the more often a participant uses a label, the better they will be at interpreting it. Data from this study did not support 
this assumption. Higher frequency of label use was only associated with increased correct scores in the Graph label variation. It could be that more exposure to labels made understanding a label that looked completely different easier to comprehend. This could also mean it is not safe to assume increased use of labels increases understanding.

Further research using these modified labels is needed to determine the extent of increased understanding. In the present study, participants were only required to choose between two labels. No follow up questions were asked to determine why they chose the product they did. Healthfulness of foods was based on recommendations by various health organizations ("Dietary Guidelines for Americans," 2010; "DRIs for Energy," 2005; "DRIs for Water," 2005; "Whole Grains and Fiber," 2011; "Sodium in your diet," 2013). But, many people may have a different set of personal standards as to what makes one product healthier than another.

There were some strengths of this study. First, participants were completely randomized into each label variation. Links to each survey were sent out randomly to each participant and distribution of all demographics was fairly even. Although demographic distributions were not equal with the University, there were no extreme disparities. There was a slightly higher percentage of females and many more graduate student for each variation when compared to the University. Secondly, this study compared only the affects of the nutrition facts panel. In reality, consumers can be influenced by a number of things including other information/advertisements on the label and price. By limiting this study to just the NFP, influence on participant's choice was controlled.

A limitation was that the sample was restricted to college students. Research 
shows that those of lower income and education levels may have the biggest barrier to understanding nutrition labels (Perez-Escamilla et al., 2002). Future research must expand to a greater population and other regions. Another limitation is that the participants had a 50\% chance of guessing the correct answer. Future studies should include more options or ask specific nutrition questions about the label in order minimize chances of guessing correctly.

With the FDA considering changes to the NFP, this study has some practical implications. The FDA should look into ways to make the NFP less complicated. Consumers should be able to glance quickly at the label and know immediately if the food is a healthy choice or not.

\section{Conclusion}

Results of this study confirm that modifications to nutrition facts panels can increase likelihood of identifying the healthier option when comparing two similar foods. Graph based labels were created to make the calorie distribution between macronutrients more visual as well as create a less complicated way to display percent daily values. Traffic light based labels were created to highlight healthy, moderate, and unhealthily levels of those nutrients that have had healthy intake level recommendation set by various health organizations. Future research is necessary to expand into a large population that includes multiple socioeconomic statuses and various education levels. These finding may be beneficial to the FDA as they move forward with changes to the current NFP. 


\section{References}

1. United States Food and Drug Administration. Inspections, compliance, enforcement, and criminal investigations for the nutrition labeling and education act requirements. http://www.fda.gov/ICECI/Inspections/InspectionGuides/ucm074948.htm Published February, 1995. Updated April 30, 2009. Accessed March 26, 2014.

2. FDA staff. Guidance for industry: A food labeling guide. U.S. Food and Drug Administration. www.fda.gov/FoodLabelingGuide. Published Sept, 1994, Updated February 25, 2014. Accessed March 26, 2014.

3. CDC staff. Obesity trends among u.s. adults between 1985 and 2010. Retrieved from http://www.cdc.gov/obesity/data/adult.html. Updated August 6, 2013. Accessed March 26, 2014.

4. Ogden CL, Carroll MD, Kit BK, Flegal KM. Prevalence of childhood and adult obesity in the united states, 2011-2012. JAMA. 2014;311(8):806-814.

doi:10.1001/jama.2014.732.

5. Hu F. Overweight and obesity in women: health risks and consequences. J Women's Health. 2003;12(2);163-172.

6. Finkelstein EA, Trogdon JG, Cohen JW, Dietz W. Annual medical spending attributable to obesity: Payer-and service-specific estimates. Health Affairs. 2009;28(5):822-831. doi: 10.1377.hlthaff.28.5.w822.

7. Kromhout D, Menitti A, Hugo K, Sans S. Prevention of coronary heart disease by diet and lifestyle: Evidence from prospective cross-cultural, cohort, and intervention studies. Circulation. 2002;105(7):893-898. Doi: 10.1161/hc0702.103728.

8. Neuhouser MN, Kristal AR, Patterson AR. Use of food nutrition labels is associated with lower fat intake. J Am Diet Assoc. 1999;99:45-53. doi:10.1016/S00028223(99)00013-9.

9. Ollberding NJ, Wolf RL, Contento I. Food label use and its relation to dietary intake among US adults. J Am Diet Assoc. 2011;111:S47-S51. doi: 10.1016/j.jada.2011.03.009.

10. Satia JA, Galanko JA, Neuhouser ML. Food nutrition label use is associated with demographic, behavioral, and psychosocial factors and dietary intake among african americans in north carolina. J Am Diet Assoc. 2005;105:392-402. doi:10.1016/j.jada.2004.12.006. 
11. Wills JM, Schmidt DB, Pillo-Blocka F, Cairns G. Exploring global consumer attitudes toward nutrition information on food labels. Nutr Rev. 2009;67:102. doi: $10.1111 / \mathrm{j} .1753-4887.2009 .00170$.

12. Obesity Working Group. Calories count report of the food and drug administration working group on obesity. 2004; 1-38.

http://www.fda.gov/ohrms/dockets/ac/04/briefing/4039b1_01_calories\%20count. pdf. Accessed March 26, 2014.

13. Perez-Escamilla R, Haldeman L. Food label use modifies association of income with dietary quality. $J$ Nutr. 2002;132(4):768-772.

14. FDA staff. Food labeling: Revision of the nutrition and supplement facts labels. Federal Registrar. https://www.federalregister.gov/articles/2014/03/03/201404387/food-labeling-revision-of-the-nutrition-and-supplement-facts-labels. Updated March 3, 2014. Accessed March 26, 2014.

15. Cowburn G, Stockley L. Consumer understanding and use of nutrition labelling: A systematic review. Public Health Nutr. 2004;8(1), 21-28. doi:10.1079/PHN2004666.

16. White J, Thomson G, Signal L. Front-of-pack nutrition labelling: Where to now? $N Z$ Med J. 2010;123(1324):12-16. http://www.nzma.org.nz/journal/123-1324/4395/. Accessed March 26, 2014.

17. Borgmeier I, Westenhoefer J. Impact of different food label formats on healthiness evaluation and food choice of consumers: a randomized-controlled study. $B M C$ Public Health. 2009;9(184):1-12. doi:10.1186/1471-2458-9-184.

18. Thorndike AN, Sonnenberg L, Riis J, Barraclough S, Levy DE. A 2-phase labeling and choice architecture intervention to improve healthy food and beverage choices. Am J Public Health. 2012;102:527-533. doi:10.2105/AJPH.2011.300391.

19. U.S. Department of Agriculture and U.S. Department of Health and Human Services. Dietary guidelines for americans. 7th Edition. Washington, DC: U.S. Government Printing Office; 2010.

20. National Research Council. Dietary reference intakes for energy, carbohydrate, fiber, fat, fatty acids, cholesterol, protein, and amino acids (macronutrients). Dietary Reference Intakes. Washington, DC: The National Academies Press; 2005.

21. National Research Council. Dietary reference intakes for water, potassium, sodium, chloride, and sulfate. Dietary Reference Intakes. Washington, DC: The National Academies Press; 2005: 269-395. 
22. American Heart Association staff. Whole grains and fiber. American Heart Association.

http://www.heart.org/HEARTORG/GettingHealthy/NutritionCenter/HealthyDiet Goals/Whole-Grains-and-Fiber_UCM_303249_Article.jsp. Published January 24, 2011. Accessed September 17, 2013.

23. United States Food and Drug Administration (2013) Sodium in your diet: using the nutrition facts label to reduce your intake. http://www.fda.gov/Food/IngredientsPackagingLabeling/LabelingNutrition/ucm3 15393.htm. Updated April 18, 2013. Accessed March 26, 2014.

24. Dove LL. (2011). Top 10 groceries americans buy. How stuff works. http://tlc.howstuffworks.com/family/10-groceries-americans-buy.htm. Published February 15, 2011. Accessed March 26, 2013.

25. Planning Research and Policy Analysis. University december 2013 facts. Illinois State University. 2013;1-2.

26. Feunekes GIJ, Gortemaker IA, Willems AA, Lion R, van den Kommer M. Front-ofpack nutrition labelling: Testing effectiveness of different nutrition labelling formats front-of-pack in four European countries. Appetite. 2008;50,:57-70. doi:10.1016/j.appet.2007.05.009.

27. Childs CM. Federal regulation of the "smart choices program": Subjecting front-ofpackage nutrition labeling schemes to concurrent regulation by the fda and the ftc. Boston University Law Review. 2012;90(6):2403-2426.

28. Hersey JC, Wohlgenant KC, Arsenault JE, Kosa KM, Muth MK. Effects of front-ofpackage and shelf nutrition labeling systems on consumers. Nutrition Reviews. 2013;71(1):1-14. doi:10.1111/nure.12000.

29. Todd JE, Variyam JN, Decline in consumer use of food nutrition labels. Economic Research Report Number 63, Economic Research service, United States Department of Agriculture. 2008;1-27. 


\section{CHAPTER II}

\section{REVIEW OF RELATED LITERATURE \\ Introduction}

Obesity is a major health concern in the United States that develops into other problems such as insulin resistance, dyslipidemia, hypertension, high cholesterol, and certain cancers $(\mathrm{Hu}, 2003)$. These diseases are for the most part, preventable with healthy diet and exercise (Kromhout, Menitti, Hugo, \& Sans, 2002). To promote healthy eating, the United States implemented the Nutrition Labeling and Education Act of 1990. This act mandates that all packaged food display a standardized label. The purpose of mandatory labeling is to inform consumers of their purchases so they may make educated decisions about food consumption(“Inspections, Compliance," 1995; "Guidance for Industry," 1994). Unfortunately, rates of obesity have continued to rise since implementation of the labeling act. Studies have looked into reasons why the nutrition facts panels (NFP) are ineffective and have found similar results (Wills, Schmit, PillBlocka, \& Cairns, 2009; Perez-Escamilla \& Haldeman 2002). The following reviews are presented in order to support the hypothesis that current NFP can be improved upon to increase label utilization and therefore improve diets. An important note is that this literature review encompasses research conducted on the entire food label, including health claims, which are not included in the NFP but do dictate consumer purchasing. 


\section{Nutrient Level Recommendations}

There is a plethora of information on the Internet regarding what is healthy and what is not. With so much available information, it can be easy for someone to become confused or obtain false beliefs in regards to a healthy diet. Fortunately, there are some researched-based organizations that have worked to compile basic nutrient recommendations based on how nutrients affect the body.

According the United States Department of Agriculture's and United States Department of Health and Human Services’ Dietary Guidelines for Americans (2010), a healthy diet encompasses a variety of nutrients. The following are nutrient recommendations within these guidelines. Kilocalories eaten should not exceed kilocalories expended to prevent weight gain leading to obesity. Added sugars in the diet should be limited since foods high in added sugars tend to lack more important nutrients. Currently the average American's diet consists of about 16\% kilocalories from added sugars, possibly attributing to high rates of obesity. Total fat content of the diet is recommended to be within $20-35 \%$ of one's daily kilocalorie intake while saturated fat is recommended to be less than $10 \%$ of total kilocalories. High saturated fat intake is related to high levels of cholesterol, which leads to cardiovascular disease. Both cholesterol and trans fat in the diet were found to increase levels of low-density lipoprotein (LDL) cholesterol levels in the blood. Therefore, consumption of any trans fats is discouraged and cholesterol recommendations are restricted to 200-300 mg a day. Current sodium intakes are much greater than suggested, which can lead to high blood pressure. High blood pressure increases the risk of cardiovascular disease and kidney failure. The Dietary Guidelines for Americans recommendations for sodium are extrapolated from 
research by the Institute of Medicine. Both of these organizations suggest a sodium intake between 1,500 $\mathrm{mg}$ and 2,300 $\mathrm{mg}$ per day. These numbers come from positive results from Dietary Approaches to Stop Hypertension diet studies. Finally, fiber helps increase satiety, boost gastrointestinal function, and controls blood sugar levels. It is recommended that intake equal 25-38 grams per day for women and men respectively. Currently, consumption is below these recommended levels ("Dietary Guidelines," 2010).

A study conducted by Sacks et al. (2001) measured blood pressure levels of participants as they consumed different levels of sodium. They found that as sodium intake decreased, so did blood pressure. Similar results were found by the Academy of Nutrition and Dietetics (2014). They reviewed fifteen studies that found reductions in high blood pressure with less salt intake. In addition, the Academy (2014) reported another four out of five studies that directly linked reduction in blood pressure to reduced sodium intake.

The Institute of Medicine and the National Research Council (2005) conduct and review nutrient intake studies to recommend healthy levels of different nutrients, or Dietary Reference Intakes. Dietary reference intakes for macronutrients are as follows. Kilocalorie intake levels are recommended to be at or below the individual's estimated energy requirement ("Dietary Reference Intakes for energy," 2005). This is to prevent unnecessary weight gain, a problem that can lead to type II diabetes, hypertension, coronary heart disease, stroke, gallbladder disease, osteoarthritis, and some cancers. High sugar intakes have been related to dental carries, cancer, obesity, and hyperlipidemia. These organizations recommend that intake of added sugars be less than $25 \%$ of total 
calories. Intakes higher than this level can inhibit intake of other essential nutrients. Specific maximal calorie recommendations for total fat, saturated fat, and trans fat have not been established. Research has not shown any intake levels of these nutrients needed to prevent disease. Instead, they recommend an Acceptable Macronutrient Distribution Range of $20-35 \%$ of daily kilocalories for total fat. This is to promote diets lower in fat, which have been found to lower the risk of obesity and obesity-related diseases. Diets high in saturated fats raise LDL cholesterol levels and percent body fat levels. These studies have also shown a linear increase in LDL cholesterol levels when trans fat consumption increased. Finally, high levels of cholesterol in the diet not only raise LDL cholesterol, but also increase the ratio of total cholesterol to high-density lipoprotein cholesterol. Therefore, saturated fat, trans fat, and dietary cholesterol should be avoided. Studies conducted for dietary reference intakes for Water, Potassium, Sodium, Chloride, and Sulfate (2005) found that the body is able to tightly control levels of sodium, resulting in the need for minimal amounts to be replaced each day. From these studies, an Adequate Intake level was determined to be $1,500 \mathrm{mg}$ sodium per day to cover losses. A Tolerable Upper Level was set at 2,300 $\mathrm{mg}$ per day to prevent high blood pressure and kidney problems.

Johnson et al. (2009) wrote a scientific statement released by the American Heart Association conducted a review on sugar consumption statistics. They found that sugar consumption has been on the rise since 1944 and the average American consumes about 355 kilocalories per day in added sugar. At this high sugar intake, reduced levels of vitamins such as vitamin $\mathrm{A}$, calcium, iron, and zinc have been noted. They recommend restricting added sugar to 100 and 150 grams a day for women and men respectively. As 
part of a heart healthy diet, the American Heart Association (2011) recommends that cholesterol be limited to $200 \mathrm{mg}$ per day. Increases in fiber are also supported. It was determined that soluble fiber helps reduce the risk of CVD because of its ability to bind with LDL cholesterol and remove it from the blood stream. Furthermore, the American Heart Association released a statement written by Greenwood et al. (2013) regarding a study published in their Journal Stroke. This study found that every seven-gram increase in fiber reduced the risk of stroke by seven percent.

A position paper by Slavin (2008) released by the Academy of Nutrition and Dietetics agreed with fiber recommendations created by the United States Department of Agriculture in the Dietary Guidelines for Americans (2010). After reviewing multiple studies, Slavin (2008) made the conclusion that fiber helps to reduce problems and risks of cardiovascular disease, obesity, gastrointestinal problems, and diabetes.

It is evident that over consumption of certain nutrients can affect the body in a variety of ways, possibly leading to obesity and disease. Other nutrients, such as fiber, work in the opposite way. Nutrient levels for kilocalories, total fat, saturated fat, trans fat, added sugars, sodium, cholesterol, and fiber all need to be considered when looking at a food label to determine how "healthy" it is.

\section{Demographics of Food Label Users}

Research has found that those who use the food label tend to belong to certain demographic populations. Ollberding, Wolf, and Contento (2011) looked into the prevalence of food label use and compared the diets of label users to non-label users using the National Health and Nutrition Examination Survey. Women, those with a higher education, and those with higher incomes were found to use food labels more 
often than their counterparts. A study conducted by Satia, Galanko, and Neuhouser (2005) found similar results when comparing label use to diet quality in the African American population in North Carolina. In addition, those with a high self-efficacy to eat healthier tended to use food labels more often than others. Neuhouser, Kristal, and Patterson (1999) conducted phone interviews to determine if food label use was effective at promoting a healthy diet. Again, this study found that people who most often use nutrition labels were women, those with an education beyond high school, and people who believed a healthy diet was related to cancer and disease prevention. More specifically, Todd and Variyam (2008) compared label use within age groups when the NLEA was implemented in 1994-1995 and then again, ten years later, in 2005-2006. It was determined that 20-29 year olds in 2005-2006 used food labels less than 20-29 year olds in 1995.

Existing literature provides evidence that certain demographic populations have been reached by the current NFP. However, improvements to the format of the NFP must ensure that other populations may benefit as well. It is important that all consumers understand the nutrition information provided to increase healthy food choices.

\section{Diets of Food Label Users}

Research has compared diets of "label-user's" to "non-user's" and found that label-user's diets more closely follow the healthy recommendations of the American Heart Association (Johnson et al., 2009). Ollberding et al. (2011) discovered the labelusers in their study tended to consume diets lower in total kilocalories, total fat, saturated fat, sugar, sodium, and cholesterol, and higher in fiber than those not using labels. Satia et al. (2005) had comparable results: label-users consumed more fruits and vegetables, less 
total fat, and less saturated fat than their non-label using counterparts. Additionally, Neuhouser et al. (1999) found that participants categorized as label-users reported lower total fat in the diet.

A study by Temple, Johnson, Recupero, and Suders (2011) looked into effects of nutrition labels on food choices and energy intake during a buffet lunch. Participants were randomly selected to eat one of two lunches. One provided nutrition labels for all foods offered, and the other did not. After lunch, weights and energy levels were calculated to determine how much food had been consumed. It was found that the group consuming the lunch without nutrition labels consumed the most energy. It is important to understand that the use of NFP has aided in healthier food choices. By creating a more readable NFP, more labels may potentially be put it to good use.

\section{Barriers to Label Use}

While some find NFPs helpful, others do not understand the information being conveyed. Research has found barriers that prevent some individuals from accurately interpreting the many aspects of the nutrition label. A review by Wills et al. (2009) summarized views of nutrition labels from different countries. Consumer perceptions about United States' nutrition labels were analyzed. Wills et al. (2009) provided unpublished raw data gathered from the International Food Information Council Foundation (2006) on understanding, views, and the use of nutrition labels. Researchers found that $58 \%$ of consumers used nutrition labels when purchasing foods, but only one quarter of those consumers found the label easy to understand. Two thirds of label users stated they only looked at the caloric information on the label. It was also determined that consumers do not use the percent daily values in the nutrition facts panel because they are 
too confusing. Consumers favored the amount per serving column instead(Wills et al., 2009). The Obesity Working Group (2004) a subcommittee for the Food and Drug Administration conducted focus groups to gain a better idea of how people use nutrition labels. They also found that many people were confused by the percent daily values or did not believe those numbers pertained to them.

Cowburn and Stockley (2004) also reviewed studies about consumer understanding of nutrition labels in different countries. Use of nutrition labels were high when comparing unfamiliar foods and when avoiding certain nutrients. Lack of time and understanding were reasons for not using the label. Technical and numerical terminology also tends to confuse consumers. Obscure terms such as sodium compared to salt, carbohydrates compared to sugar, fatty acids, and cholesterol added to the complexity. And again, percent daily values were not well understood. Overall, it was deemed that understanding of nutrition labels is moderate to low.

A study conducted by Fuenekes, Gortemaker, Willems, Lion, and van den Kommer (2008) investigated different types of nutrition label formats and how well consumers understand the information presented. Although this study took place in Europe and analyzed front-of-pack nutrition labeling popular on that continent, results indicated that people who are less knowledgeable about nutrition have a more difficult time comprehending labels with a lot of detailed information. Consumers tend to be confused by information that is too technical or contains a lot of numbers and percentages. The NFP must instead present clear, concise information that can be interpreted in a matter of seconds. 
In a study by Perez-Escamilla et al. (2002), food label use was compared to the dietary practices of those is varying income groups. Information was gathered from the Continuing Survey of Food Intake and the Individuals and Diet Health Knowledge Survey. Analysis of information demonstrated that those with lower incomes tended to not use food labels as often as wealthier individuals. People in low-income groups were less likely to have completed high school, had little nutrition knowledge, and were more likely to have participated in the food stamp program. These qualities could be barriers in their ability to interpret the nutrition label.

When interviewing low-income people in New Zealand, Signal, Lanumata, Robinson, Tavila, Wilton, and Mhurchu (2008), noticed that this group felt isolated by some labeling systems used in their country. The "healthy tick" system uses a check mark on the front of packages to indicate the item meets certain health standards. When asked, the participants stated that healthy tick appeared most often on brand name products, not items they could afford. They did not understand what exactly the tick represented, nor had the time to decipher this information. However, when asked about the traffic light system, an alternative system in use, many supported it. Due to the variety of languages spoken in that country, a system containing information represented by well-known colors was a welcome labeling initiative.

This information emphasized the fact that those who have attained a lower level of education are at the greatest disadvantage when it comes to interpreting NFPs. Any modifications must be decipherable by those who have not completed a nutrition class, or received a high school diploma. They also should be understood by anyone who speaks a different language. 


\section{Proposed Changes to Current Food Labels}

The Food and Drug Administration (FDA) recently released proposed changes to food labels (2014). The only changes made since implementation twenty years ago were the addition of trans fat in 2006. Proposed changes reflect the latest research by the Institute of Medicine and Daily Guidelines for Americans. The intent is to update percent daily values to current recommendations for each nutrient. The FDA recognizes research that shows consumers do not understand percent daily values (Obesity Working Group, 2004). In spite of this research, they propose to move percent daily values to the left side of the label, making them more prominent. They also propose to remove the table at the bottom of the label that provides reference ranges for macronutrients for a 2000 and 2500-calorie diets. Some positive improvements include alterations to serving sizes. Packages of food that are labeled as multiple servings, even though they can be completely consumed at one time, will now be labeled as a single serving. In addition, calories from fat will be removed because the amount of fat has been determined to be less important than the type of fat. In its place, calories will be shown in larger font. Additions to the label will include amounts of vitamin D and potassium, two nutrients that are important in the diet, but are often lacking.

A study by Lando and Lo (2013) analyzed effectiveness of proposed food label modifications by the FDA. Nutrition Facts Panels that can be labeled as one or two servings per container, but can be reasonably eaten all at one time were modified. Results found that participants were better at identifying the healthier label when serving size was listed as only one serving instead of two. This study is important in that the proposed 
modifications to nutrition facts panels are a step in the right direction toward better understanding.

\section{Front-of-Package Labeling}

The current food-labeling trend is to create a condensed way to illustrate a product's nutrient profile on the front the food package. This trend is just now beginning to emerge in the United States, with the food industry's "Smart Choices" program (Childs, 2012) and the NuVal system (Hersey, Wohlgenant, Arsenault, Kosa, \& Muth, 2013). Countries such as Australia, New Zealand, and some in Europe have already conducted studies on popular front-of-package (FOP) labeling systems.

White, Thomson, and Signal (2010) discussed the major issues Australia and New Zealand are facing in the efforts to standardize FOP labeling. Professionals from the health sector tend to support the traffic light labeling system, while food and beverage manufacturers support the Daily Intake Guide. The food and beverage manufacturers disapprove of the traffic light labeling system because it is believed that red lights on food packages will discourage purchases. Therefore, lobbying against traffic light FOP labels has begun, putting the goal of a standardized FOP labeling system on hold.

In a Boston University Law review, Childs (2012) discussed the regulation and control the FDA and the Federal Trade Commission have over information presented on food labels. Because consumer purchases are greatly influenced by information on the front of packages, companies have started to sell "healthy logos" to food manufactures. These logos are placed on the front of packages indicating they are a "healthy" food. Although this can be helpful information, some foods displaying healthy logos have may not be particularly healthy. This review demanded the FDA and Federal Trade 
Commission to collaborate on a standardized FOP labeling system for the United States. A possible threat to effective FOP labeling systems is the lobbying power of the food and beverage industry in the United States. If FOP labeling design is put in the hands of food manufacturers, this information could be used as advertisements for that food instead of the education of the consumer. Changes to the current NFP on the back of packages that can be understood by the majority of the population, and are not influenced by industry, would then be increasingly important.

An article by Lobstein and Davies (2008) discussed the difficulty of standardizing a "nutrient-profiling system" for FOP food labels. The authors indicated that some systems are great for determining high and low levels of a specific nutrient. These are beneficial when comparing two similar items but may not be helpful for comparisons of different food products. Other systems create one total score for a food product by analyzing levels of nutrients based on current recommendations. While this may seem all encompassing, certain factors may be overlooked. For example, a food containing a low amount of added sugars may receive a good score even if the percentage of fat is high. Lobstein and Davies recommend that any labeling system should ensure: understanding labels only takes 4-10 seconds; all social, ethnic, and age groups are able to interpret information correctly; nutrients are based on dietary guidelines; healthy choices are promoted.

\section{Traffic Light Labeling System}

The traffic light labeling is a popular labeling system that scrutinizes four nutrients; total fat, saturated fat, sugar, and sodium and then categorizes them as high, medium, or low based on set standards. A review by Louie, Flood, Rangan, Hector, and 
Gill (2008) describes the traffic light labeling system in detail. Foods high in the unhealthy nutrients receive a red light. Foods with a medium to moderate amount of the nutrients receive an amber light. And finally, foods low in the unhealthy nutrients receive a green light. This is to promote moderation by encouraging consumers to choose more foods with green lights and less with red. Total fat, saturated fat, sugar, and sodium were selected because they are associated with chronic disease. The authors caution that colors must be determined based on added sugars and not those that come naturally in dairy or fruits.

Roberto, Bragg, and Schwartz (2012) conducted a study which compared the "facts up front" labeling system supported by the food industry with traffic light labels to compare consumer understanding between the two. Conditions included no label, traffic light, traffic light plus, Facts-up-Front, and Facts-up-Front plus. The traffic light plus system labels green nutrients as healthy, amber as moderate, and red as unhealthy levels. This difference is to include protein and fiber, both of which would be better at higher levels. The traffic light plus label was best at helping consumers determine between levels of specific nutrients, even with protein and fiber included.

A study conducted by Pettigrew, Pescud, and Donovan (2012) implemented a traffic light system in Australian elementary schools and monitored the effectiveness on the overall healthiness of food choices for children. All items that would be considered "red" were removed from the lunchroom and "green" items were promoted. Parents, principals and lunchroom workers filled out questionnaires on use and understanding of the traffic light system. In general, it was found that the traffic light system was easy to understand and would be accepted if it were extended into the grocery market. It is also 
important to note that those of lower socioeconomic status were most receptive to the traffic light system. Because this demographic population tends to use the NFP less often, having their support is imperative.

Research by Ares et al. (2012) evaluated different nutrition label's ability to capture consumers' attention by graphic design. Information was shown in traffic light form, tables, and paragraphs. Response time and accuracy were measured. Table and traffic light forms took less time to classify than the paragraphs. Also, the traffic light system took about five seconds less to process overall than all forms and had a slightly increased number of correct responses. Kelly, Hughes, Chapman (2009) found similar results in their study. Standard traffic light system, traffic light system with an overall rating, percent daily values, and color-coded percent daily values were compared to assess the most effective FOP labeling system for consumers. Participants were shown a food label with one of the four labeling formats and asked to assess if it was high, medium, or low in fat, saturated fat, sodium, and sugar. The traffic light with the overall rating was found to have to most correct responses.

Another study conducted by Maubach and Hoek (2008) compared two front of pack labeling systems, traffic lights and percent daily intake, to determine which would be best utilized by consumers. Participants were asked to give an opinion of two different cereals based on the NFP and either one of the front of pack label variations shown to them. When compared to the control, a negative opinion for the least healthy cereal was found in both variables, but was stronger for the traffic light variables. This study, again, identifies the traffic light system as the forerunner of labeling systems. 
Because of the disparity between food manufacturers and health officials on traffic light labeling systems and the daily guideline amounts, both groups were required to submit research to the Council of Australian Governments either supporting their claim or rebutting the opposition. White and Signal (2012) reviewed the studies submitted to determine which system would be more effective. It was concluded that the traffic light system would be most beneficial for individuals with lower income to make healthier purchasing decisions when compared to the daily intake guide.

All of these studies show that the traffic light labeling system is best at influencing healthier food choices, especially for those with lower education levels and of lower socioeconomic status. This holds true multiple times over when compared to the percent daily intakes labeling systems that have been developed and supported by food and beverage manufacturers (Roberto et al., 2012; Kelly et al., 2009; Maubach et al. 2008; White et al., 2012). It is hoped that a modified NFP reflecting the traffic light labeling system will reflect similar results.

\section{How to Correctly Use Pie Graphs}

A review by Spence (2005) analyzed studies on people's ability to accurately judge space in pie charts. While many studies have proven inconclusive, a few others have found improved comprehension. Spence deduces from his studies that the pie graph... "is a simple information graphic whose principle purpose is to show the relationship of a part to the whole" (p. 363) and therefore can be sufficient when used properly.

Hunt and Mashhoudy (2008) provide suggestions for proper use of pie charts. The authors suggest that the goal of pie charts is to show how different parts make up a 
whole. Sorting parts based on size is recommended to make reading the graph easier. Starting with the first and largest, part of the pie at the 12 o'clock position and working clockwise, to the smallest piece of the pie, should improve interpretation of the pie chart. Hunt et al., notes that a correctly labeled pie chart is also easier to read. Data labels are recommended to be outside the pie while actual percentages are represented inside the pie. Ervin (2011) conducted a review analyzing the differences in participant's ability to judge space within a pie chart compared to bar graphs. Ervin was able to surmise that the pie chart is better at part-to-whole comparisons and bar charts are better for part-to-part comparisons.

The goal of modifications to NFPs it to create something that is simple for those of all ethnicities and education levels to understand. A nutrition facts panel in pie graph format may be the solution. These studies show that pie graphs are great for displaying simple information and people tend to be able to judge areas, or pieces of the pie, well within pie graphs. Because the graph's capabilities are limited to part-to-whole comparisons, only calorie containing nutrients can be displayed in the pie graph.

Overall, it is clear that something must be done to improve NFPs. Currently one goal is to condense all information on the front of a package for consumers. Unfortunately, how this information should be presented is up for debate. Food companies stand to be negatively affected by certain labeling systems and therefore will lobby against them (White et al., 2012). Additionally, the FDA's proposed changes to food labels continues to emphasize the use of percent daily values despite their acknowledgment that consumers do not understand them or not utilize them ("Food Labeling: Revision," 2014). Modifications to the NFP should take into consideration 
education and language differences of all Americans. By creating an easy to read NFP, more consumers might put it to use, which may potentially result in healthier diets and reduced rates of obesity. 


\section{References}

1. Hu F. Overweight and obesity in women: health risks and consequences. J Women's Health. 2003;12(2);163-172.

2. Kromhout D, Menitti A, Hugo K, Sans S. Prevention of coronary heart disease by diet and lifestyle: Evidence from prospective cross-cultural, cohort, and intervention studies. Circulation. 2002;105(7):893-898. Doi: 10.1161/hc0702.103728.

3. United States Food and Drug Administration. Inspections, compliance, enforcement, and criminal investigations for the nutrition labeling and education act requirements.

http://www.fda.gov/ICECI/Inspections/InspectionGuides/ucm074948.htm

Published February, 1995. Updated April 30, 2009. Accessed March 26, 2014.

4. FDA staff. Guidance for industry: A food labeling guide. U.S. Food and Drug Administration. www.fda.gov/FoodLabelingGuide. Published Sept, 1994. Updated February 25, 2014. Accessed March 26, 2014.

5. Wills JM, Schmidt DB, Pillo-Blocka F, Cairns G. Exploring global consumer attitudes toward nutrition information on food labels. Nutr Rev. 2009;67:102. doi:10.1111/j.1753-4887.2009.00170.x.

6. Perez-Escamilla R, Haldeman L. Food label use modifies association of income with dietary quality. J Nutr. 2002;132(4):768-772.

7. U.S. Department of Agriculture and U.S. Department of Health and Human Services. Dietary guidelines for americans. 7th Edition. Washington, DC: U.S. Government Printing Office; 2010.

8. Sacks FM, Svetkey LP, Vollmer, et al. Effects on blood pressure of reduced dietary sodium and the dietary approaches to stop hypertension (DASH) diet. $N$ Engl $J$ Med. 2001;344 (1):3-10.

9. Academy of Nutrition and Dietetics. Sodium and Blood Pressure. Evidence Analysis Library. Updates 2014. Accessed March 30, 2014.

10. National Research Council. Dietary reference intakes for energy, carbohydrate, fiber, fat, fatty acids, cholesterol, protein, and amino acids (macronutrients). Dietary Reference Intakes. Washington, DC: The National Academies Press; 2005.

11. National Research Council. Dietary reference intakes for water, potassium, sodium, chloride, and sulfate. Dietary Reference Intakes. Washington, DC: The National Academies Press; 2005: 269-395. 
12. Johnson RK, Appel LJ, Brands M, et al. Dietary sugars intake and cardiovascular health: A scientific statement from the american heart association. Circulation. 2009;120:1011-1020. doi: 10.1161/CIRCULATIONAHA.109.192627.

13. American Heart Association staff. Whole grains and fiber. American Heart Association.

http://www.heart.org/HEARTORG/GettingHealthy/NutritionCenter/HealthyDiet Goals/Whole-Grains-and-Fiber_UCM_303249_Article.jsp. Published January 24, 2011. Accessed September 17, 2013.

14. Greenwood DC, Evans CEL, Cleghorn CL, et al. Eating more fiber may lower risk of first-time stroke. Stroke. http://newsroom.heart.org/news/eating-more-fiber-maylower-risk-of-first-time-stroke?preview=fcd4. Published March 28, 2013. Accessed September 17, 2013.

15. Slavin J. Position of the american dietetic association: Health implications of dietary fiber. J Am Diet Assoc. 2008;108:1716-1731. doi:10.1016/j.jada.2008.08.007.

16. Ollberding NJ, Wolf RL, Contento I. Food label use and its relation to dietary intake among US adults. $J$ Am Diet Assoc. 2011;111:S47-S51. doi: 10.1016/j.jada.2011.03.009.

17. Satia JA, Galanko JA, Neuhouser ML. Food nutrition label use is associated with demographic, behavioral, and psychosocial factors and dietary intake among african americans in north carolina. J Am Diet Assoc. 2005;105:392-402. doi:10.1016/j.jada.2004.12.006.

18. Neuhouser MN, Kristal AR, Patterson AR. Use of food nutrition labels is associated with lower fat intake. J Am Diet Assoc. 1999;99:45-53. doi:10.1016/S00028223(99)00013-9.

19. Todd JE, Variyam JN, Decline in consumer use of food nutrition labels. Economic Research Report Number 63, Economic Research service, United States Department of Agriculture. 2008;1-27.

20. Temple JL, Johnson K, Recupero K, Suders. Nutrition labels decrease energy intake in adults consuming lunch in the laboratory. $J$ Am Diet Assoc. 2011;111:52-S55. doi: 10.1016/j.jada.2011.03.010.

21. Obesity Working Group. Calories count report of the food and drug administration working group on obesity. 2004; 1-38. http://www.fda.gov/ohrms/dockets/ac/04/briefing/4039b1_01_calories\%20count. pdf. Accessed March 26, 2014. 
22. Cowburn G, Stockley L. Consumer understanding and use of nutrition labelling: A systematic review. Public Health Nutr. 2004;8(1), 21-28. doi:10.1079/PHN2004666.

23. Feunekes GIJ, Gortemaker IA, Willems AA, Lion R, van den Kommer M. Front-ofpack nutrition labelling: Testing effectiveness of different nutrition labelling formats front-of-pack in four European countries. Appetite. 2008;50,:57-70. doi:10.1016/j.appet.2007.05.009.

24. Signal L, Lanumata T, Robinson JA, Tavila A, Wilton J, Mhurchu CN. Perceptions of new zealand nutrition labels by maori, pacific and low-income shoppers. Public Health Nutr. 2008;11(7):706-713. doi:10.1017/S1368980007001395.

25. FDA staff. Food labeling: Revision of the nutrition and supplement facts labels. Federal Registrar. https://www.federalregister.gov/articles/2014/03/03/201404387/food-labeling-revision-of-the-nutrition-and-supplement-facts-labels. Updated March 3, 2014. Accessed March 26, 2014.

26. Lando AM, Lo SC. Single-larger-portion-size and dual-column nutrition labeling may help consumers make more healthful food choices. J Acad Nutr Diet. 2013;133(2):241-250.

27. Childs CM. Federal regulation of the "smart choices program": Subjecting front-ofpackage nutrition labeling schemes to concurrent regulation by the fda and the ftc. Boston University Law Review. 2012;90(6):2403-2426.

28. Hersey JC, Wohlgenant KC, Arsenault JE, Kosa KM, Muth MK. Effects of front-ofpackage and shelf nutrition labeling systems on consumers. Nutrition Reviews. 2013;71(1):1-14. doi:10.1111/nure.12000.

29. White J, Thomson G, Signal L. Front-of-pack nutrition labelling: Where to now? $N Z$ Med J. 2010;123(1324):12-16. http://www.nzma.org.nz/journal/123-1324/4395/. Accessed March 26, 2014.

30. Lobstein T, Davies S. Defining and labelling 'healthy' and 'unhealthy' food. Public Health Nutr. 2008;12(3):331-340. doi:10.1017/S1368980008002541.

31. Louie JC, Flood V, Rangan A, Hector D J, Gill T. A comparison of two nutrition signposting systems for use in australia. NSW Public Health Bulletin. 2008;19(78):121-126. doi 10.1071/NB07118.

32. Roberto CA, Bragg MA, Schwartz MB, et al. Facts up front versus traffic light food labels: A randomized control trial. Am J Prev Med. 2012;43(2):134-141.

33. Pettigrew S, Pescud M, Donovan R. Traffic light food labelling in schools and beyond. Health Educ J. 2012;71:746-753. doi: 10.1177/0017896911424659. 
34. Ares G, Giménez A, Bruzzone F, et al. Attentional capture and understanding of nutrition labelling: a study based on response times. Int J Food Sci Nut. 2012;63(3):679-688. doi: 10.3109/09637486.2011.652598.

35. Kelly B, Hughes C, Chapman K. Consumer testing of the acceptability and effectiveness of front-of-pack food labelling systems for the Australian grocery market. Health Promot Int. 2009;24(2):120-129.

36. Maubach N, Hoek J. The effect of alternative nutrition information formats on consumers' evaluations of a children's breakfast cereal. Partnerships, Proof and Practice-International Nonprofit and Social Marketing Conference. 2008;1-8. http://ro.uow.edu.au/insm08/1. Accessed March 26, 2014.

37. White J, Signal L. Submissions to the australian and new zealand review of food labeling law and policy support traffic light nutrition labelling. Aust NZ J Public Health. 2012;36(5):446-451.

38. Spence I. No humble pie: The origins and usage of a statistical chart. J Educational and Behavioral Statistics. 2005;30(4):353-368.

39. Hunt N, Mashhoudy H. The humble pie- Half-baked or well done? Teaching Statistics. 2008;30(1):6-12.

40. Ervin CW. Pie Charts and financial communications. Information Design Journal. 2011;19(3):205-215. doi: 10.1075/iddj.19.3.02erv. 


\section{APPENDIX A \\ EMAIL SENT TO STUDENTS \\ Current Label Variation Email}

Hello, my name is Courtney Markey and I am a graduate student under the direction of Dr. Jan Murphy. I invite you to participate in my survey to help expand knowledge in the area of food labeling. This survey will inquire about age, gender, race, and knowledge of nutrition. In no way with this information be linked back to participants. Each participant will then be shown images of two similar nutrition facts panels and be asked to choose the one they believe to be healthiest. This should only take about 15-20 minutes and will help determine ways to increase understanding of how packaged foods are labeled.

If you are interested in participating in this study and are over the age of 18, please follow this link:

https://survey.lilt.ilstu.edu/TakeSurvey.aspx?SurveyID=183L154M.

Afterwards, you may enter in a drawing for a chance to win one of ten gift cards to Avanti's Italian Restaurant.

Thank you for your time,

Courtney Markey

--Courtney Markey Graduate Student/Dietetic Intern

\section{Graph Label Variation Email}

Hello, my name is Courtney Markey and I am a graduate student under the direction of Dr. Jan Murphy. I invite you to participate in my survey to help expand knowledge in the area of food labeling. This survey will inquire about age, gender, race, and knowledge of nutrition. In no way with this information be linked back to participants. Each participant will then be shown images of two similar nutrition facts panels and be asked to choose the one they believe to be healthiest. This should only take about 15-20 minutes and will help determine ways to increase understanding of how packaged foods are labeled. 
If you are interested in participating in this study and are over the age of 18 , please follow this link:

https://survey.lilt.ilstu.edu/TakeSurvey.aspx?SurveyID=7232859K.

Afterwards, you may enter in a drawing for a chance to win one of ten gift cards to Avanti's Italian Restaurant.

Thank you for your time,

Courtney Markey

--Courtney Markey Graduate Student/Dietetic Intern

\section{Traffic Light Label Variation Email}

Hello, my name is Courtney Markey and I am a graduate student under the direction of Dr. Jan Murphy. I invite you to participate in my survey to help expand knowledge in the area of food labeling. This survey will inquire about age, gender, race, and knowledge of nutrition. In no way with this information be linked back to participants. Each participant will then be shown images of two similar nutrition facts panels and be asked to choose the one they believe to be healthiest. This should only take about 15-20 minutes and will help determine ways to increase understanding of how packaged foods are labeled.

If you are interested in participating in this study and are over the age of 18, please follow this link:

https://survey.lilt.ilstu.edu/TakeSurvey.aspx?SurveyID=7232869K.

Afterwards, you may enter in a drawing for a chance to win one of ten gift cards to Avanti's Italian Restaurant.

Thank you for your time,

Courtney Markey

--Courtney Markey Graduate Student/Dietetic Intern 


\section{APPENDIX B \\ INFORMED CONSENT}

Dear Participant:

I am a graduate student under the direction of Dr. Jan Murphy in the Department of Family and Consumer Sciences at Illinois State University. I am conducting a research study to understand how to better create Nutrition Facts Panels for food labels. I am requesting your participation, which will involve fifteen to twenty minutes of your time in choosing the healthiest food label from several sets of two labels.

You must be at least 18 years or older to participate in this study. Your participation in this study is voluntary. If you choose not to participate or to withdraw from the study at any time, there will be no penalty; it will not affect you at all. Your responses are anonymous and any information that might allow someone to identify you will not be disclosed.

There are no risks involved with participation beyond those of everyday life. Although there may be no direct benefit to you, a possible benefit of your participation is to find easier to read, or faster to cognitively process ways to present nutrition facts labels which could lead to healthier choices.

If you have any questions concerning the research study, please call me at (309) 3103543 or Kevin Pietro at (309) 438-6021.

Sincerely,

Courtney Markey 
APPENDIX C

\section{SUREY LABEL PAIRS}

Current Label Variation

1. chips

Please choose the label you believe to be the healthiest

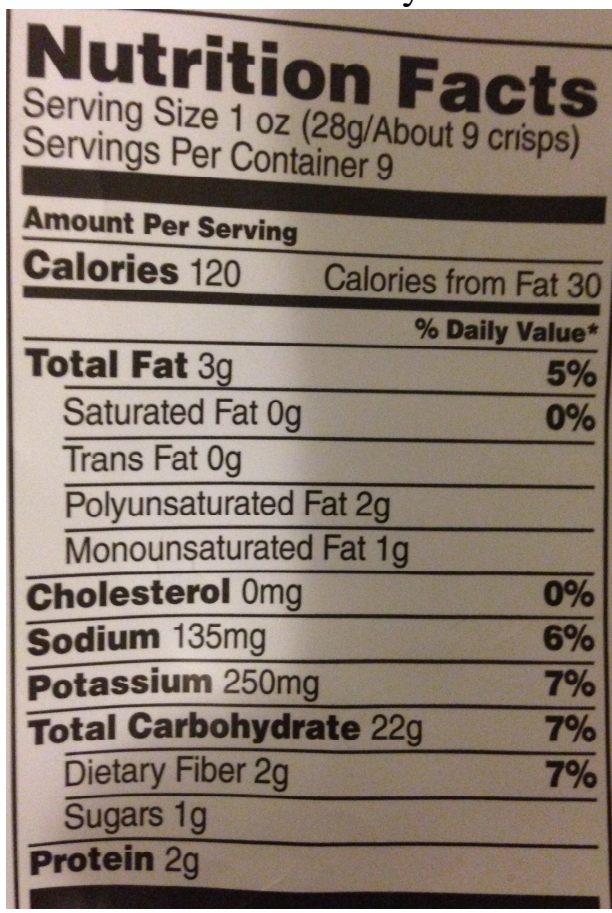

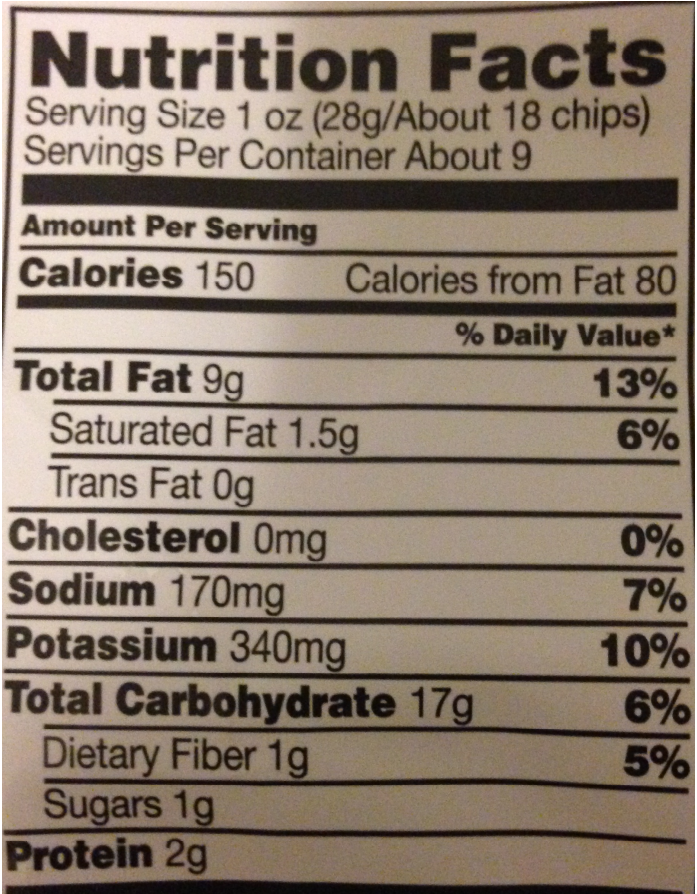

2. Deli Meat

Please choose the label you believe to be the healthiest

\begin{tabular}{|c|c|c|c|c|}
\hline \multirow{2}{*}{$\begin{array}{l}\text { Mutrition } \\
\text { Facts }\end{array}$} & Amount/Serving & $\%$ DV* & Amount/Serving & $\%$ DV* \\
\hline & Total Fat $2 \mathrm{~g}$ & $3 \%$ & Sodium $740 \mathrm{mg}$ & $31 \%$ \\
\hline \multirow{3}{*}{ Serv. Size 2 slices $(56 \mathrm{~g})$} & Sat. Fat $1 \mathrm{~g}$ & $5 \%$ & Potassium $310 \mathrm{mg}$ & $9 \%$ \\
\hline & Trans Fat Og & & Total Carb. $3 \mathrm{~g}$ & $1 \%$ \\
\hline & Polyunsat. Fat $0 \mathrm{~g}$ & & Dietary Fiber $0 \mathrm{~g}$ & $0 \%$ \\
\hline \multirow{3}{*}{$\begin{array}{l}\text { Calories } 60 \\
\text { Fat Cal. } 20 \\
\text { - Percent Daily Values (DV) are } \\
\text { based on a 2,000 calorie diet. }\end{array}$} & Monounsat. Fat Og & & Sugars $2 g$ & \\
\hline & Cholest. 25mg & $8 \%$ & Protein 89 & \\
\hline & Vitamin $\mathrm{A} 0 \%$ • Vitam & & $\%$ • Calcium 0\% • Ir & $\operatorname{ron} 2 \%$ \\
\hline
\end{tabular}




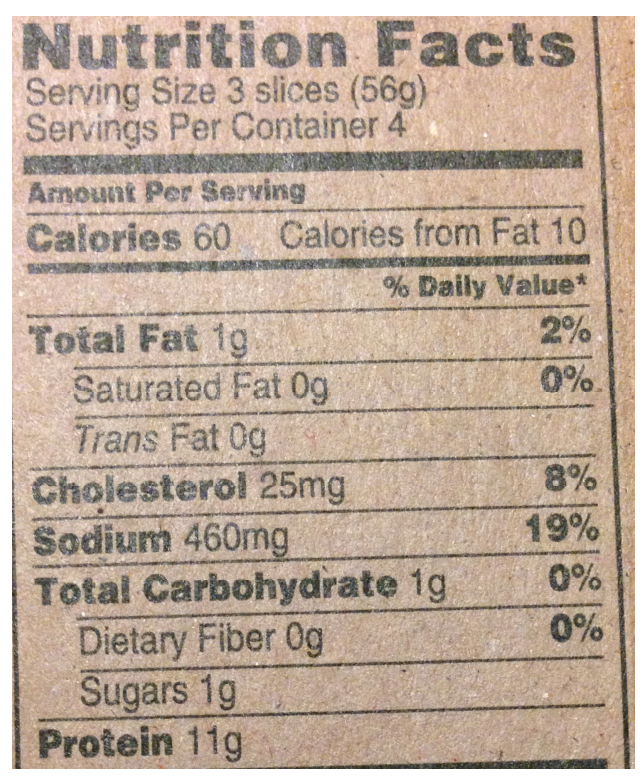

3. Peanut Butter

Please choose the label you believe to be the healthiest

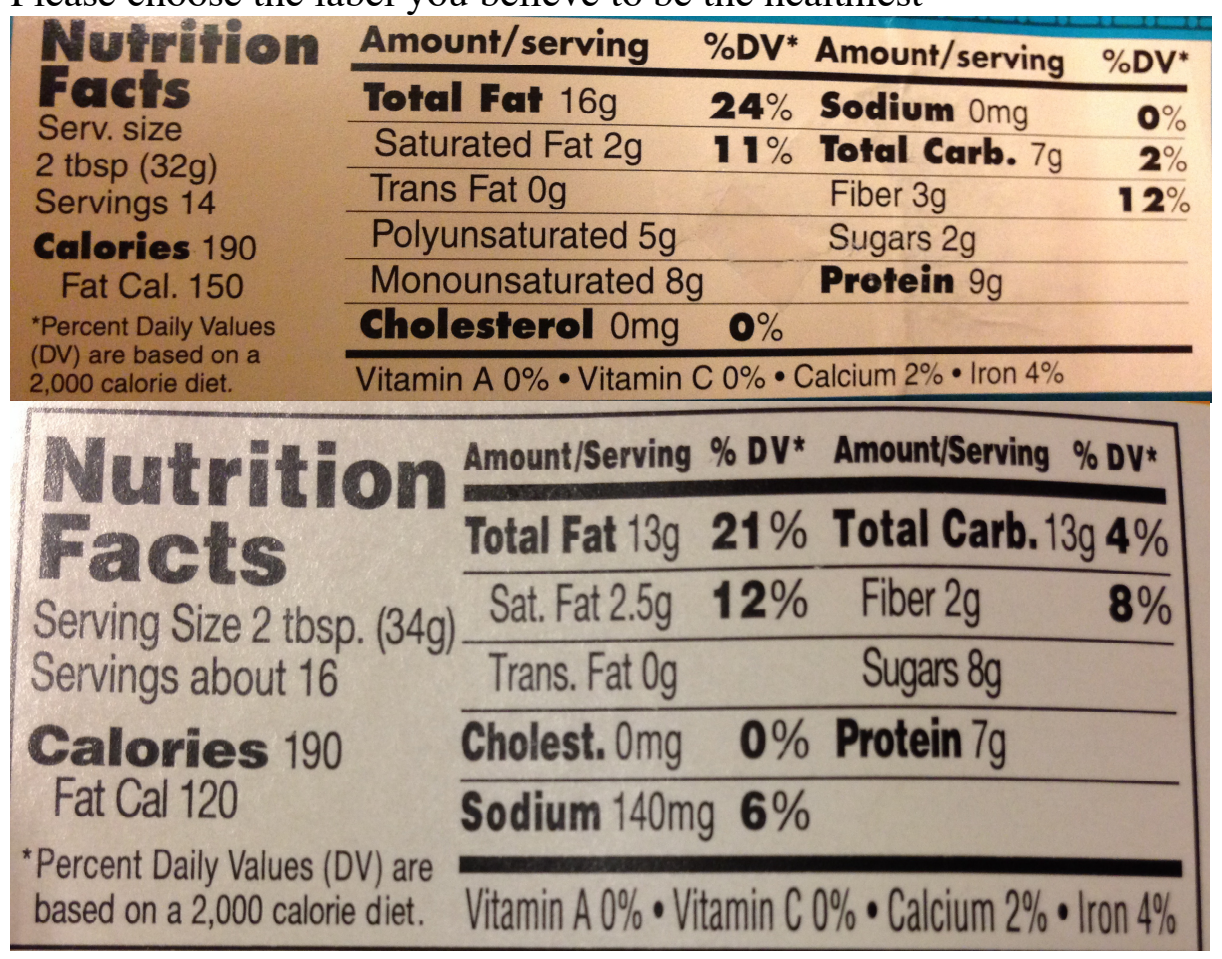


4. Frozen Dinner

Please choose the label you believe to be the healthiest

\begin{tabular}{|c|c|}
\hline $\begin{array}{l}\text { Nutrition Facts } \\
\text { Serving Size } 1 \text { Package (297 g) } \\
\text { Servings Per Container } 1\end{array}$ & $\begin{array}{l}\text { Serving Size } \\
\text { Servings } \mathrm{Pe}\end{array}$ \\
\hline Amount Per Serving & \\
\hline Calories 320 Calories from Fat 70 & $\begin{array}{l}\text { Amount Per Serving } \\
\text { Calories } 340 \text { Calories from Fat } 110\end{array}$ \\
\hline Total Fat $8 \mathrm{~g}$ & $\%$ Daily Value \\
\hline Saturated Fat $4 \mathrm{~g}$ & Total Fat $12 \mathrm{~g}$ \\
\hline $\begin{array}{l}\text { Trans Fat } 0 \mathrm{~g} \\
\text { Polvunsaturated Fat } 0 \mathrm{~g}\end{array}$ & Saturated Fat $6 \mathrm{~g}$ \\
\hline Monounsaturated Fat $2 \mathrm{~g}$ & Trans Fat $0.5 \mathrm{~g}$ \\
\hline Cholesterol $30 \mathrm{mg}$ & Cholesterol $35 \mathrm{mg}$ \\
\hline Sodium $630 \mathrm{mg}$ & Sodium $850 \mathrm{mg}$ \\
\hline Potassium $710 \mathrm{mg} \quad 20 \%$ & Total Carbohydrate $37 \mathrm{~g} 12 \%$ \\
\hline $\begin{array}{l}\text { Total Carbohydrate } 45 \mathrm{~g} 15 \% \\
\text { Dietary Fiber } 4 \mathrm{a} \\
\mathbf{1 6 \%}\end{array}$ & Dietary Fiber $3 \mathrm{~g} \quad 11 \%$ \\
\hline Sugars $8 \mathrm{~g}$ & Sugars $8 \mathrm{~g}$ \\
\hline rotein & Protein $20 \mathrm{c}$ \\
\hline
\end{tabular}

5. Juice

Please choose the label you believe to be the healthiest

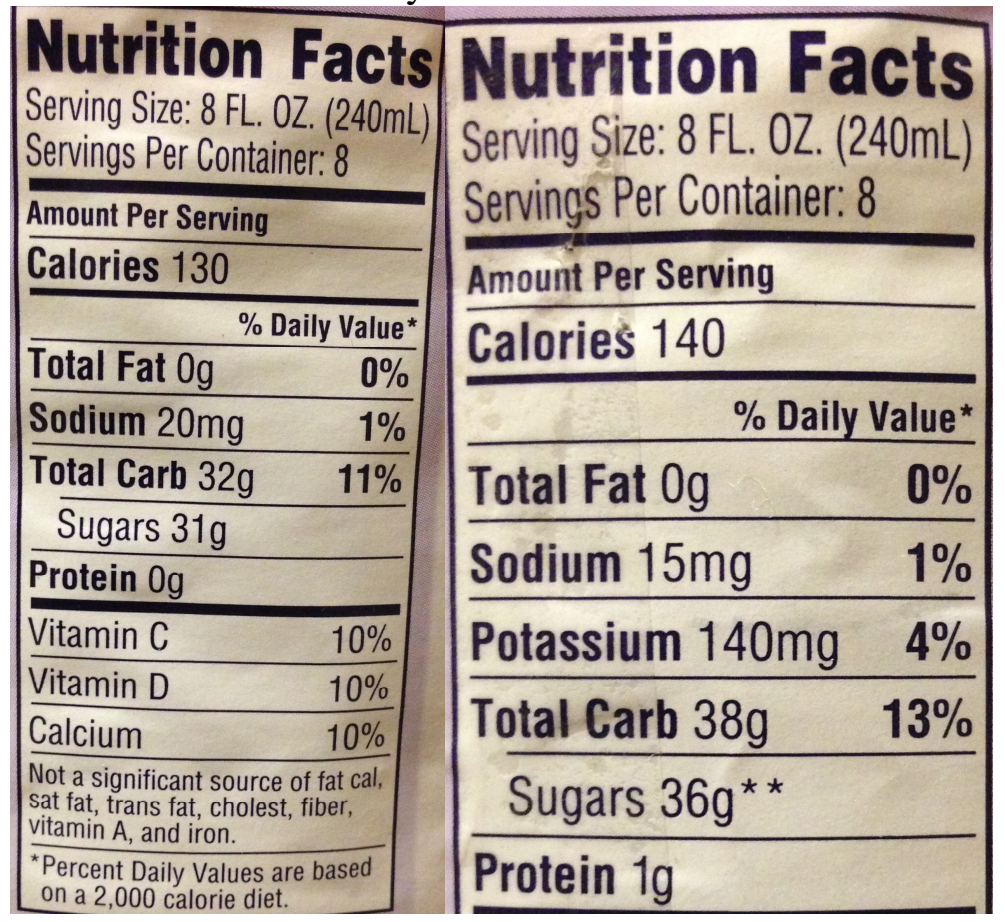


6. Cereal

Please choose the label you believe to be the healthiest

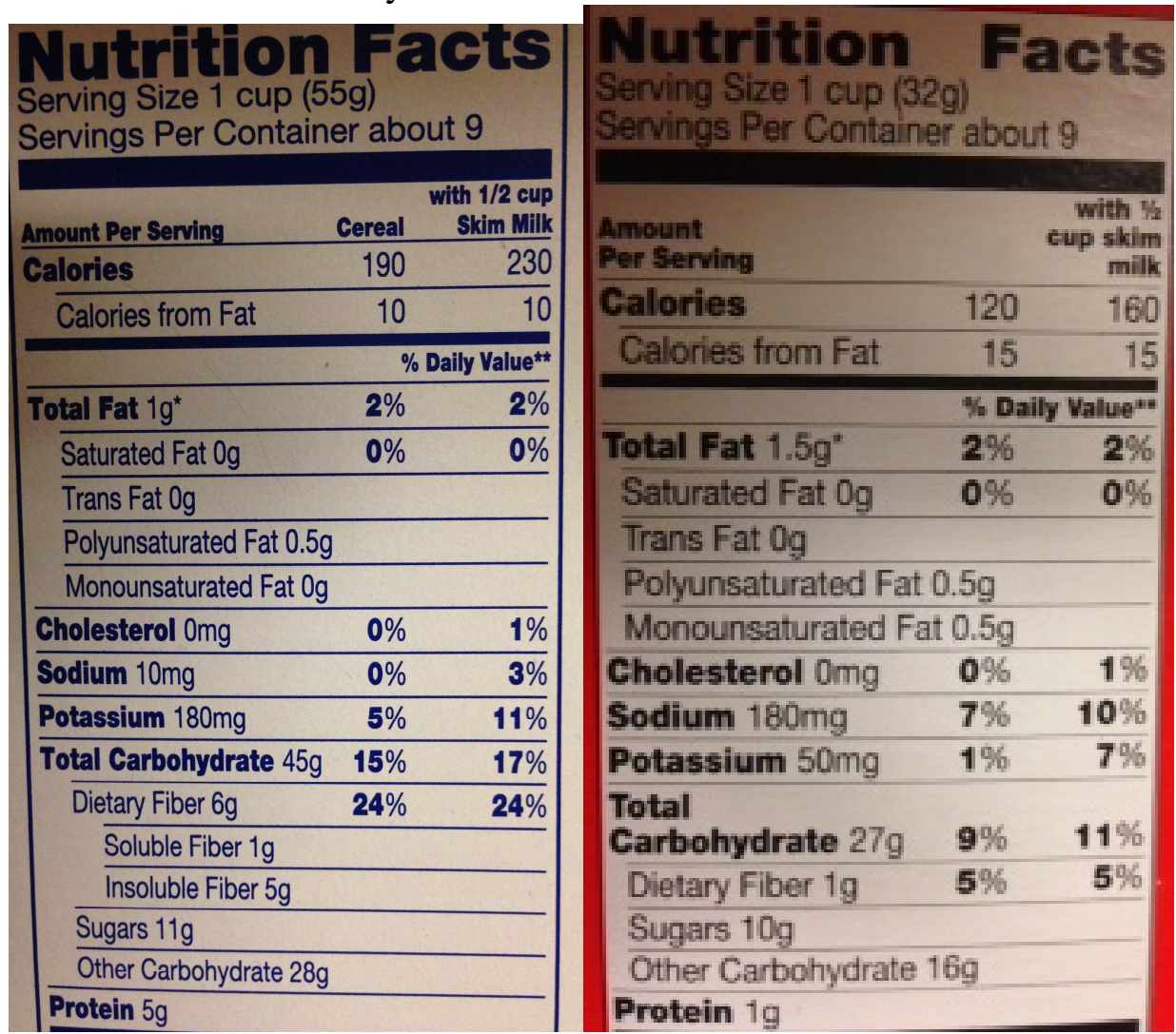

7. Butter

Please choose the label you believe to be the healthiest

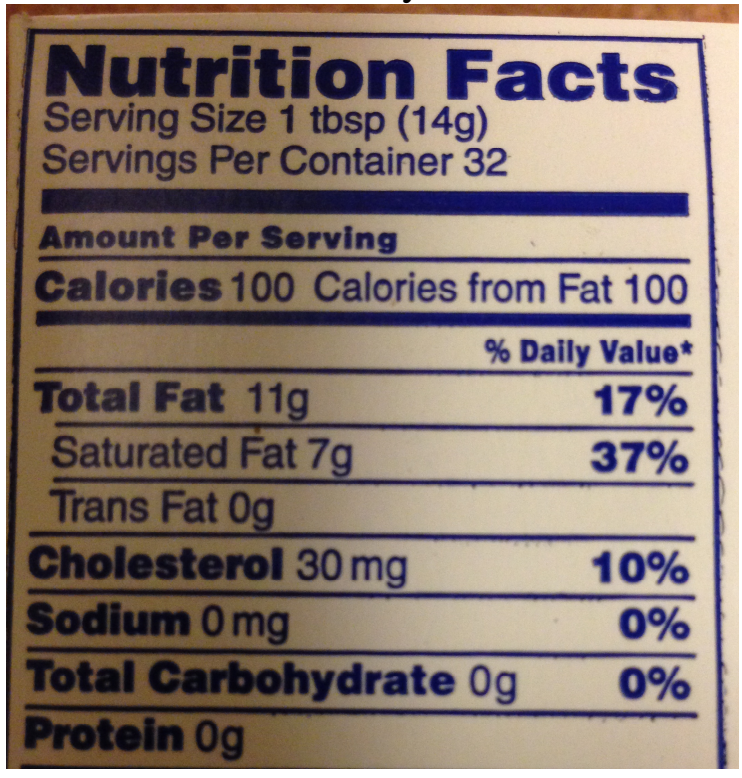




\begin{tabular}{|c|c|c|c|c|}
\hline 츰 & Anourl Serving & sor & AmountServing & \%or \\
\hline Facts & Total Fat $10 \mathrm{~g}$ & $15 \%$ & Cholest. 10mg & $3 \%$ \\
\hline Serv. Size 1 Tosp (14g) & Sat. Fat $3.5 \mathrm{~g}$ & $18 \%$ & Sodium $85 \mathrm{mg}$ & $4 \%$ \\
\hline Servings Per Container & Trans Fat og & & Total Carb. Og & $0 \%$ \\
\hline About 16 & Polyunsaturated Fat $2 g$ & & Protein 0g & \\
\hline Calories 90 & Monounsaturated Fat $4 \mathrm{~g}$ & & & \\
\hline rat vai. 90 & Vitamin A $8 \%$ & & & \\
\hline based on a 2,000 calonie diet. & Not a significant source of detary & fber, sug & ars, vitamin C, calcium a & and iron. \\
\hline
\end{tabular}

8. Bread

Please choose the label you believe to be the healthiest

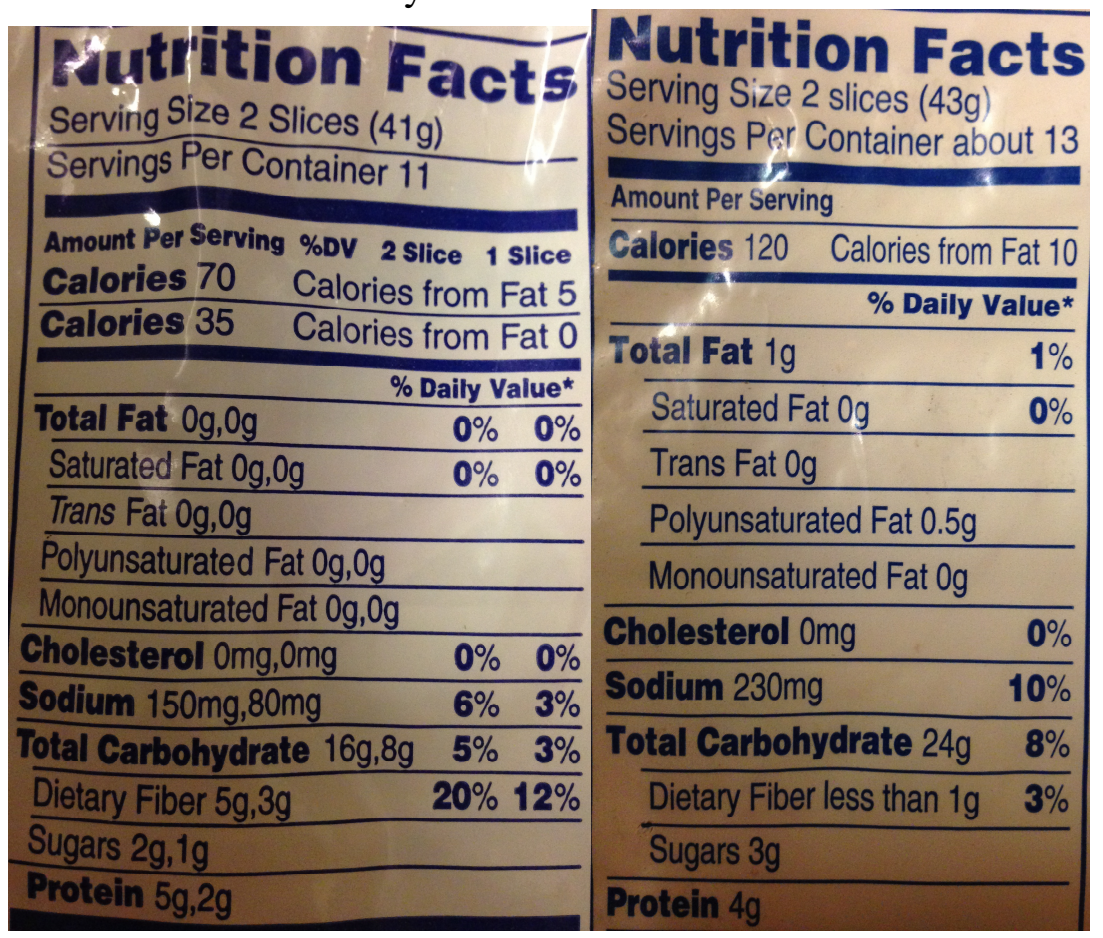




\section{Chips}

\section{Graph Variation}

Please choose the label you believe to be the healthiest

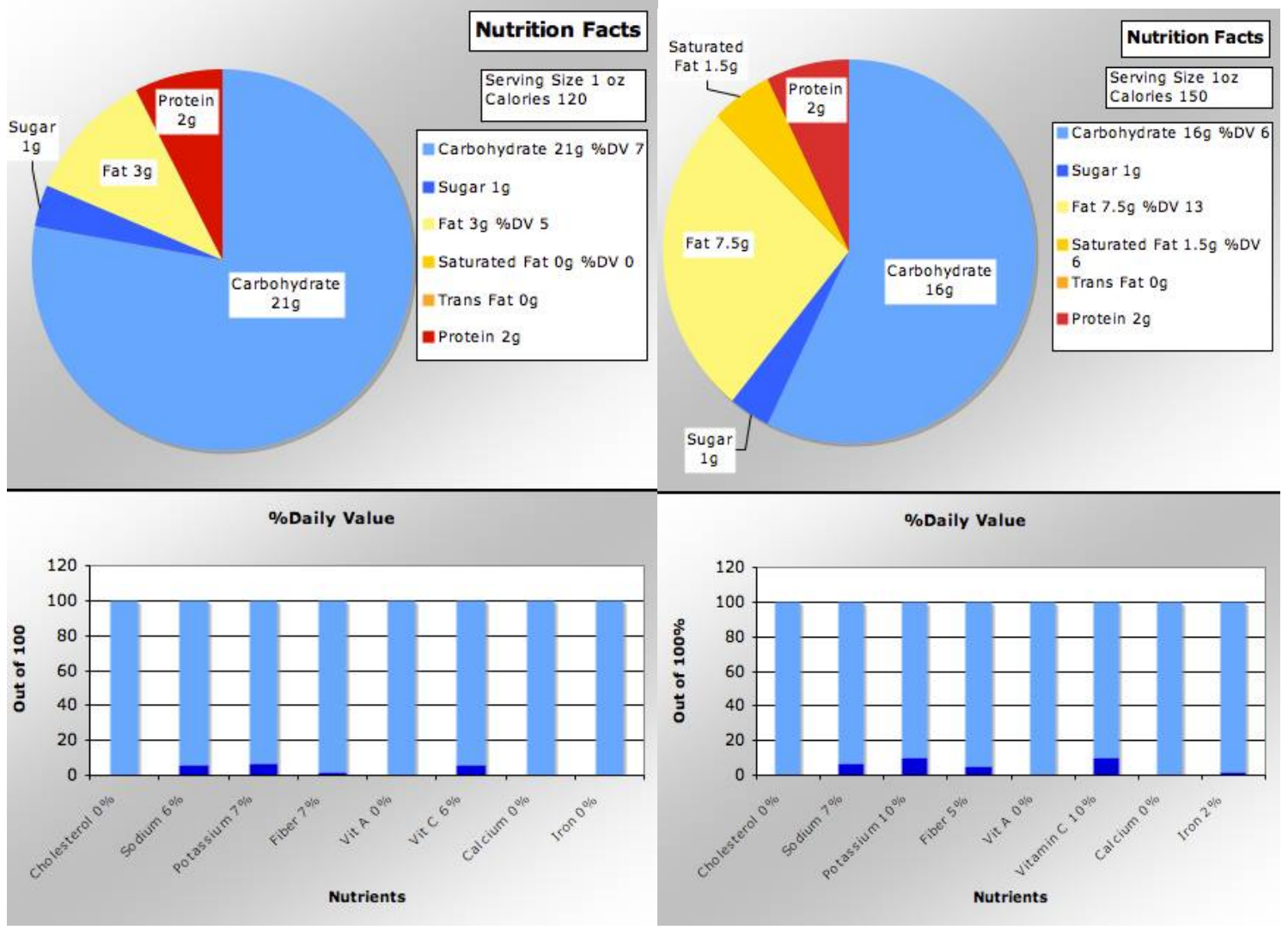


2. Deli Meat

Please choose the label you believe to be the healthiest
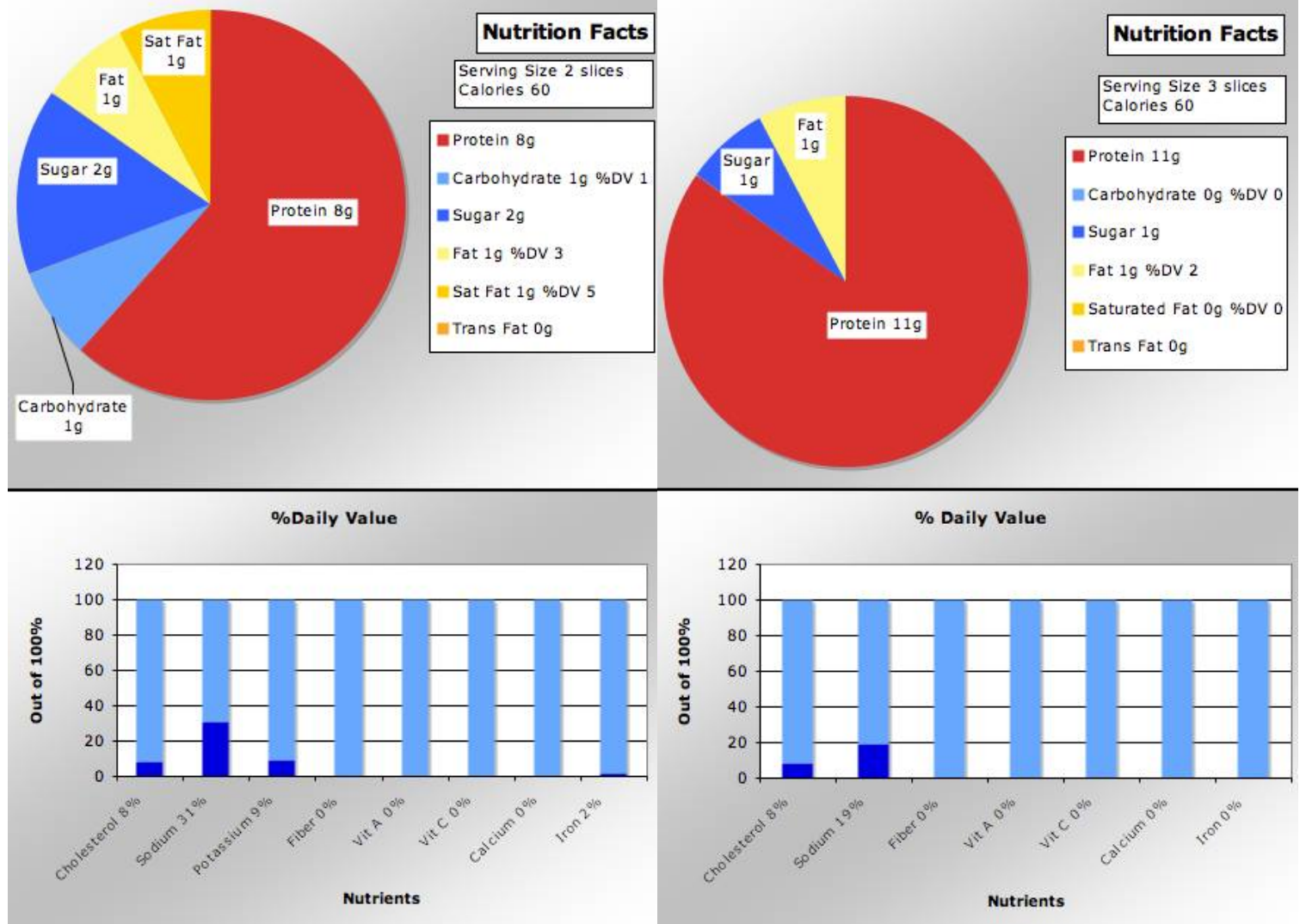


\section{Peanut Butter}

Please choose the label you believe to be the healthiest

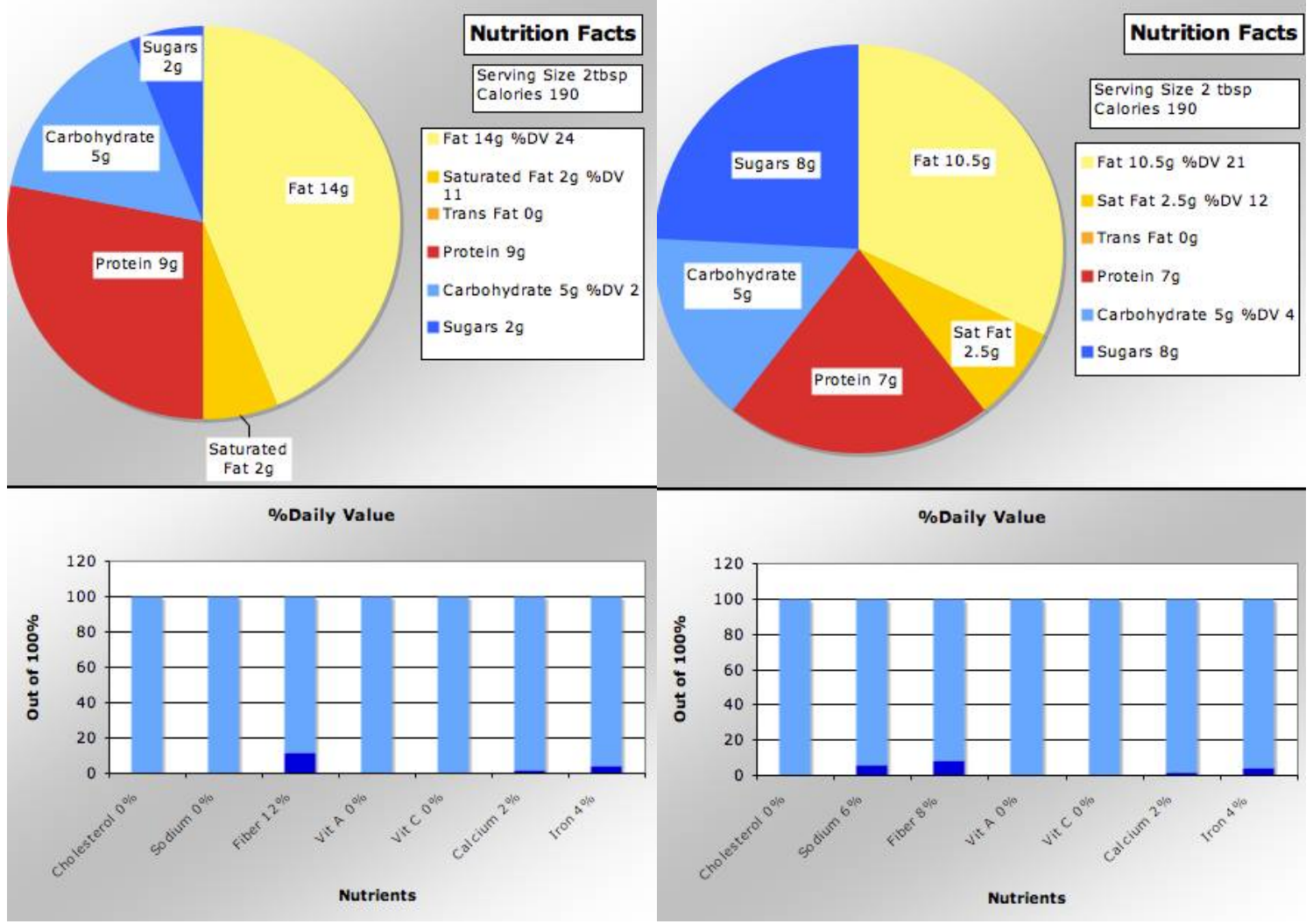




\section{Frozen Dinner}

Please choose the label you believe to be the healthiest

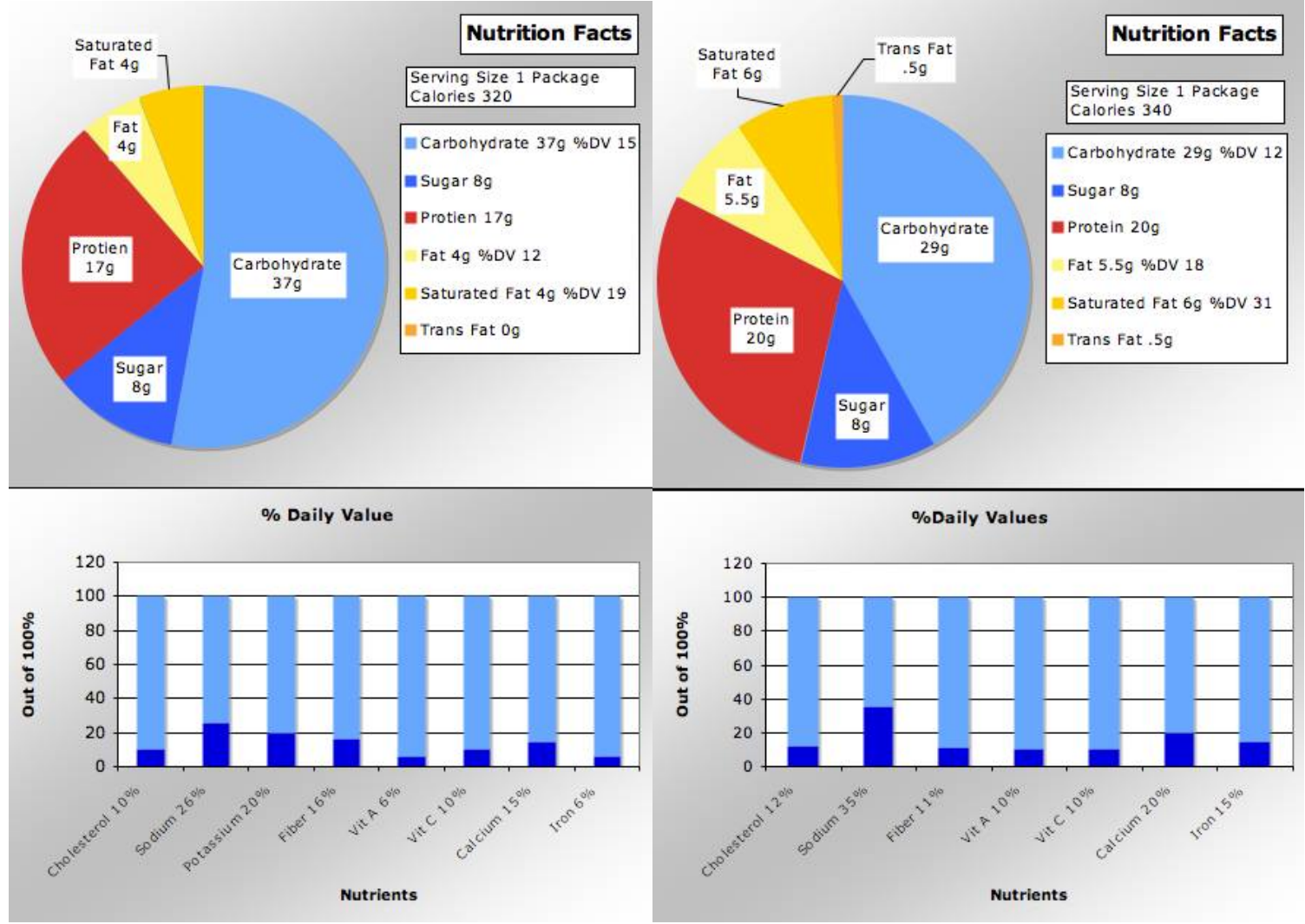




\section{Juice}

Please choose the label you believe to be the healthiest

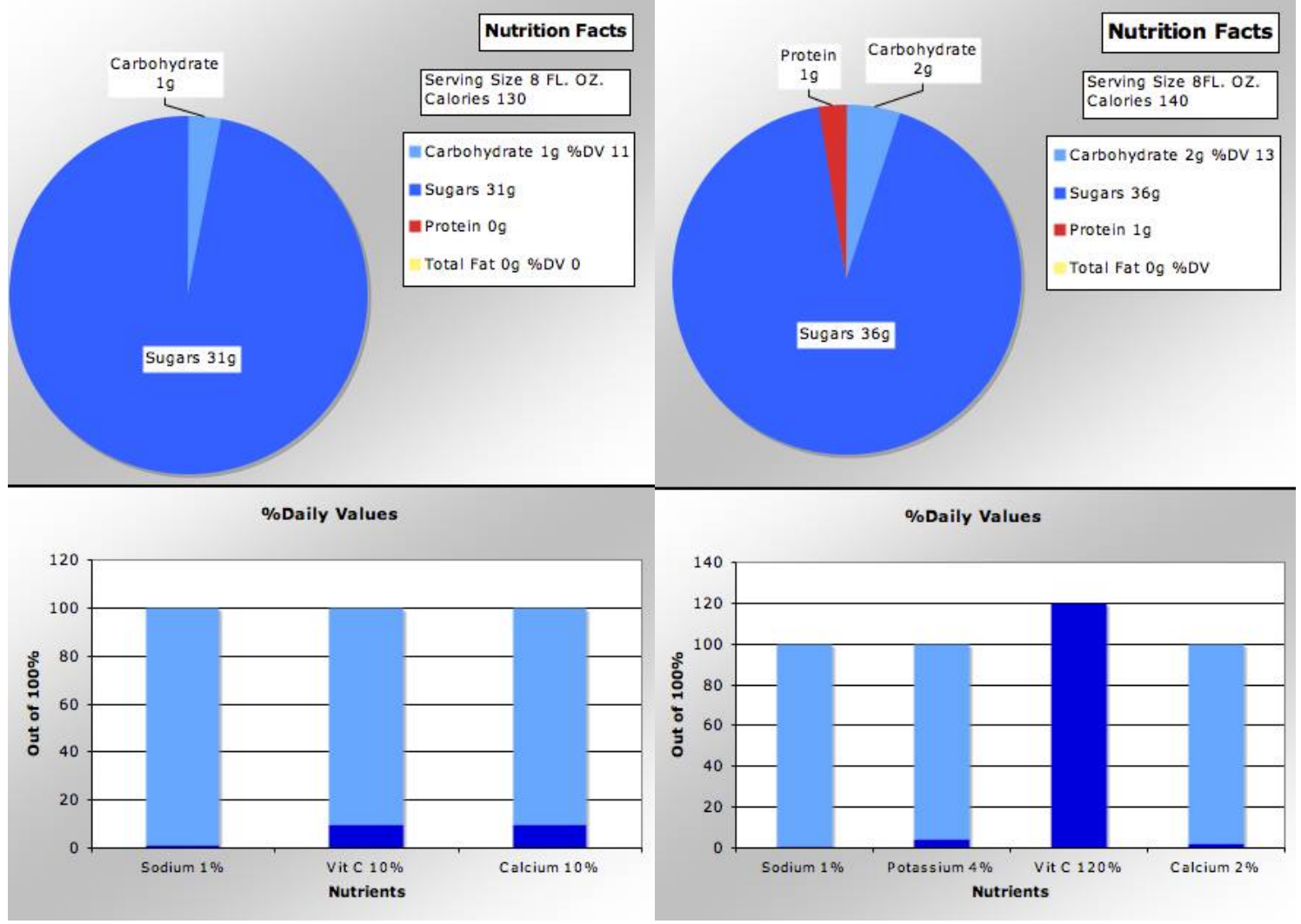




\section{Cereal}

Please choose the label you believe to be the healthiest

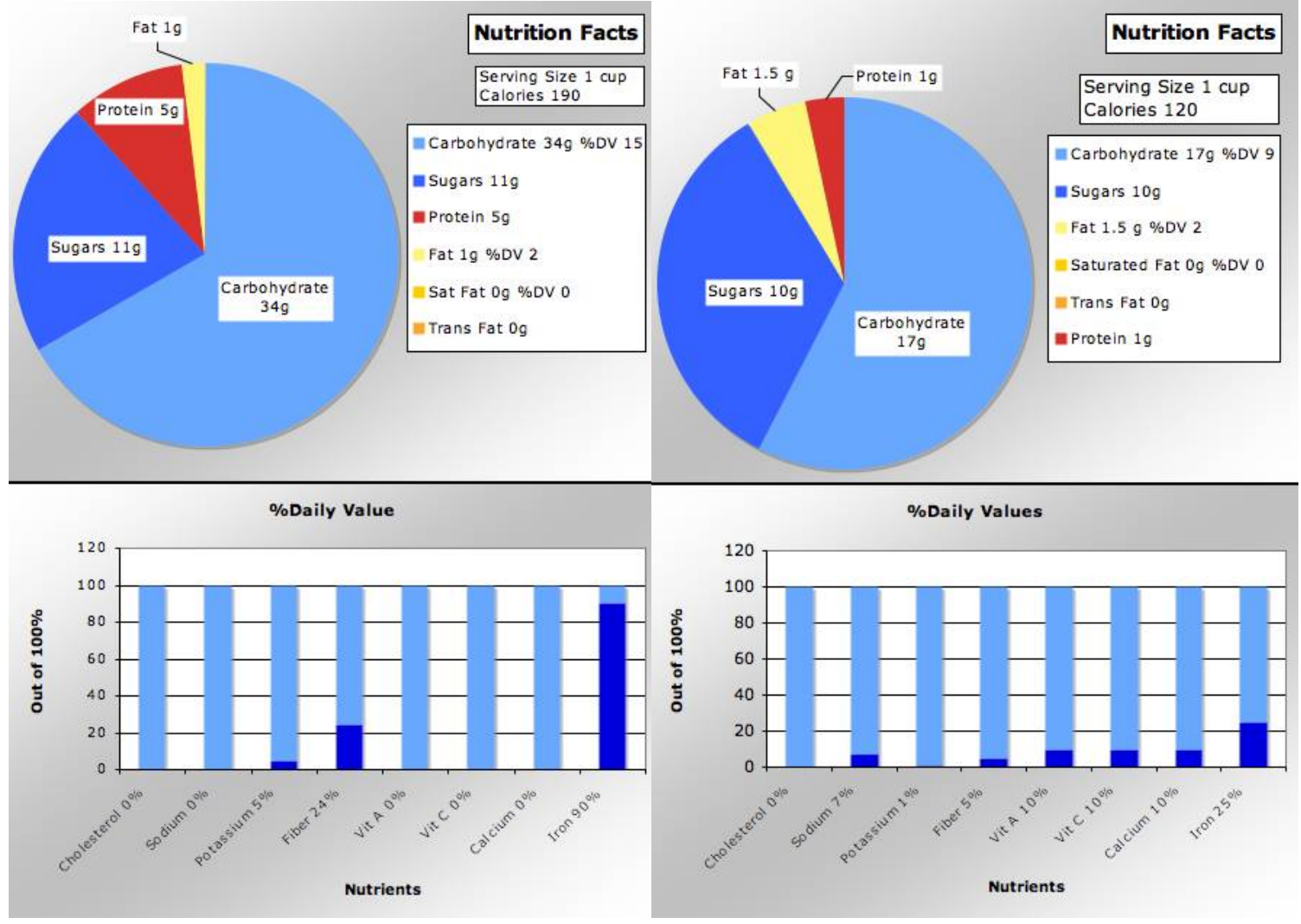


7. Butter

Please choose the label you believe to be the healthiest

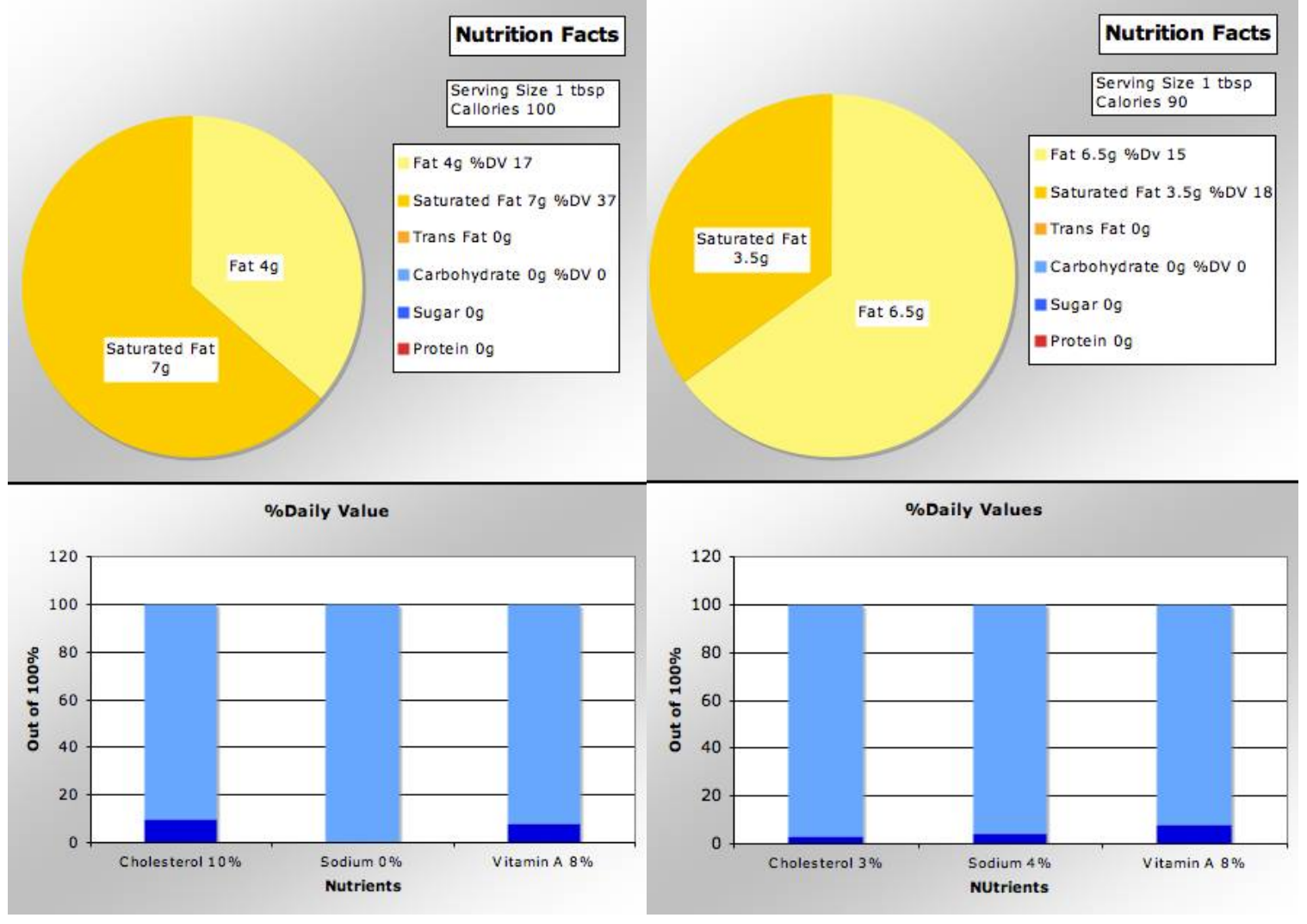




\section{Bread}

Please choose the label you believe to be the healthiest

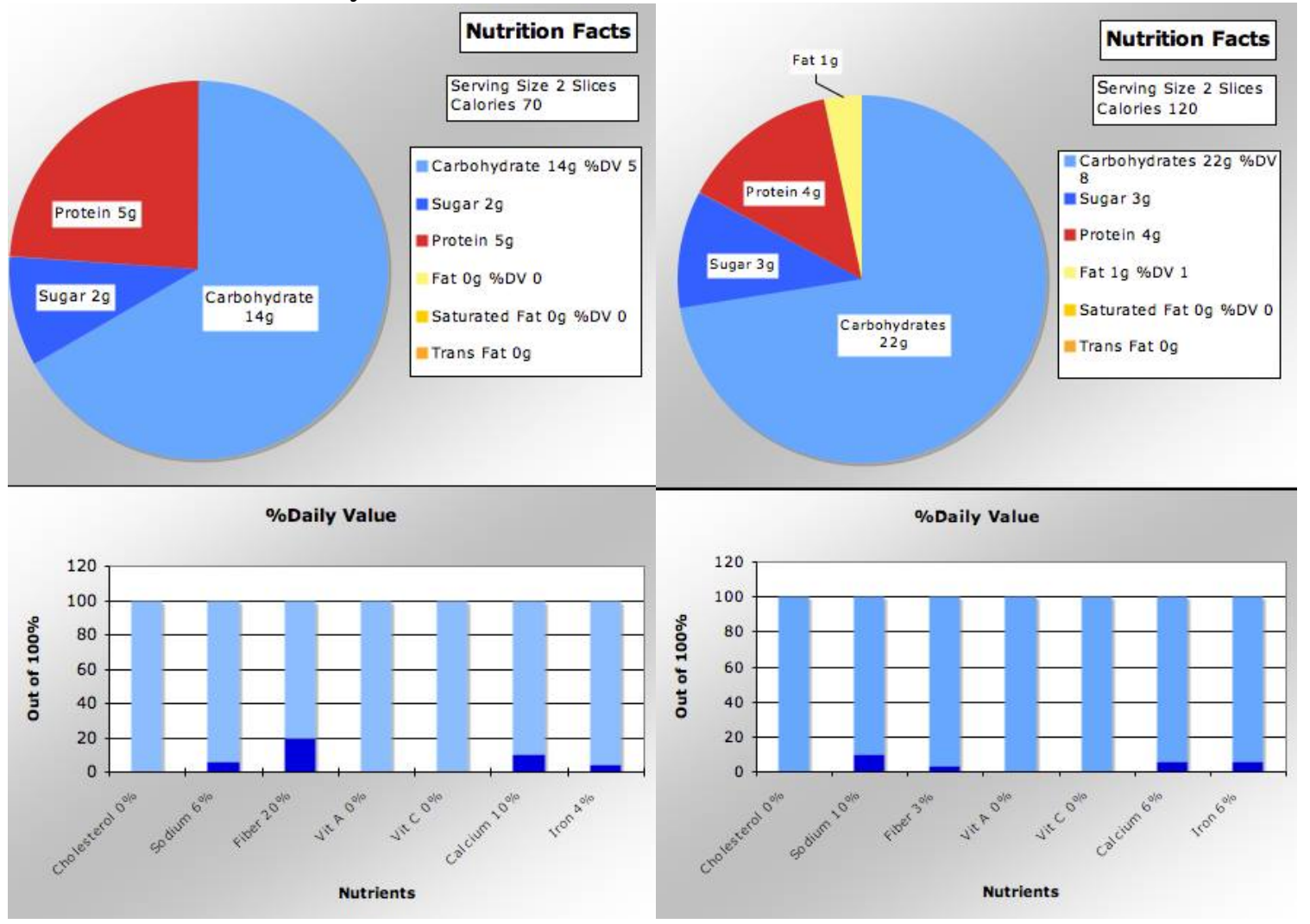


1. Chips

Traffic Light Variation

Please choose the label you believe to be the healthiest

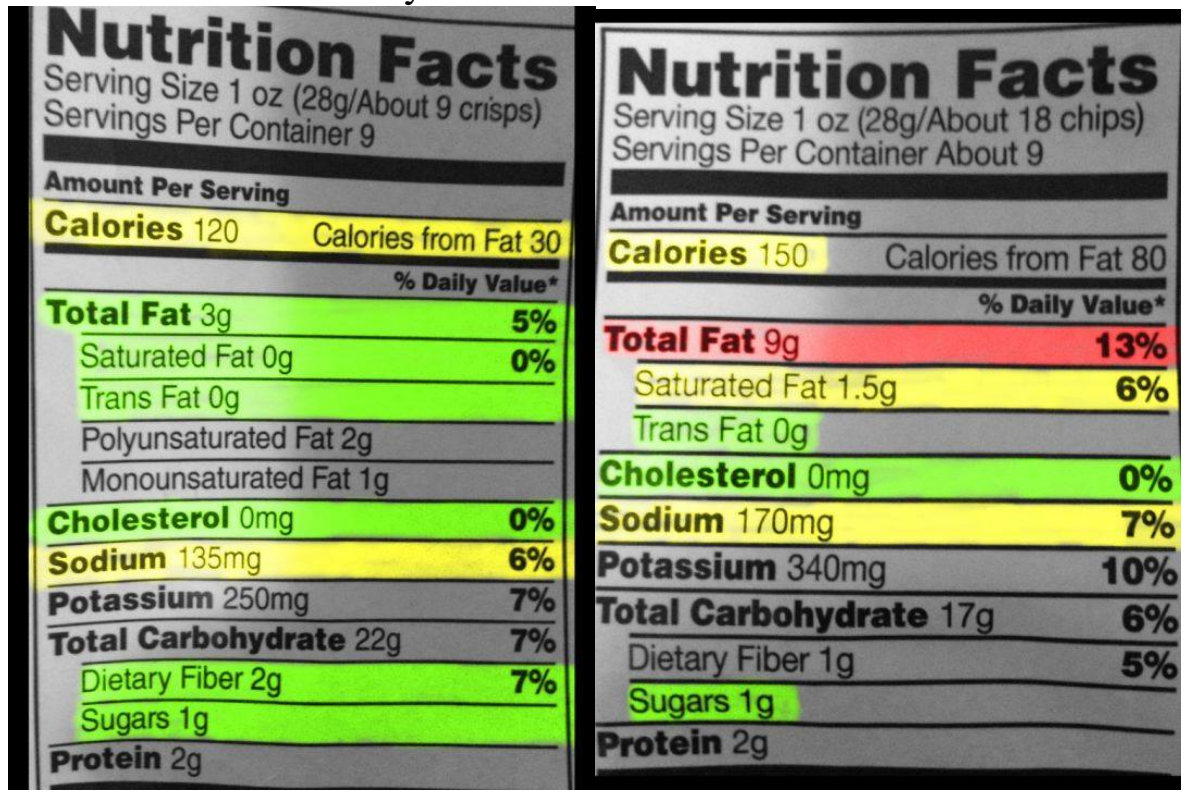

\section{Deli Meat}

Please choose the label you believe to be the healthiest

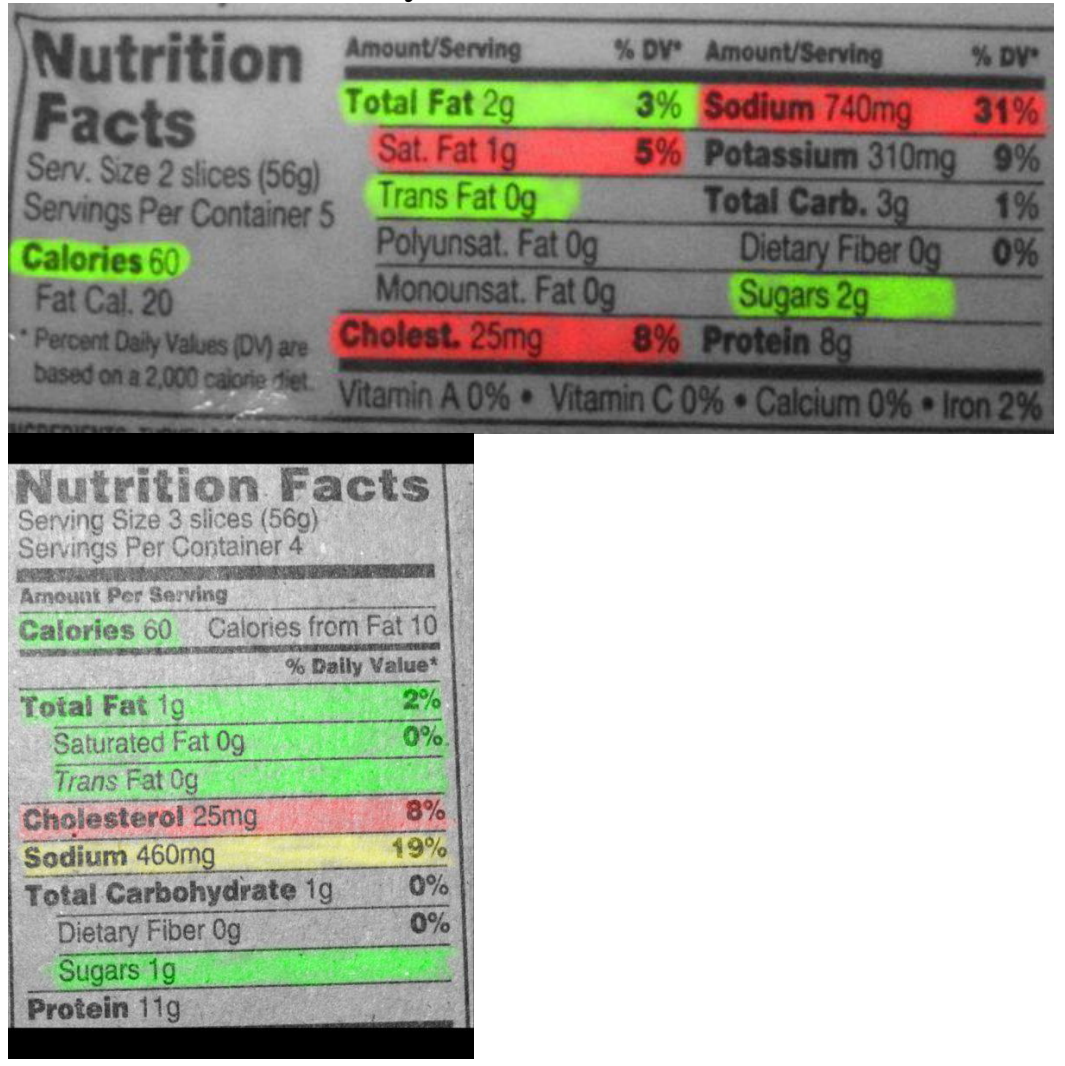


3. Peanut Butter

Please choose the label you believe to be the healthiest

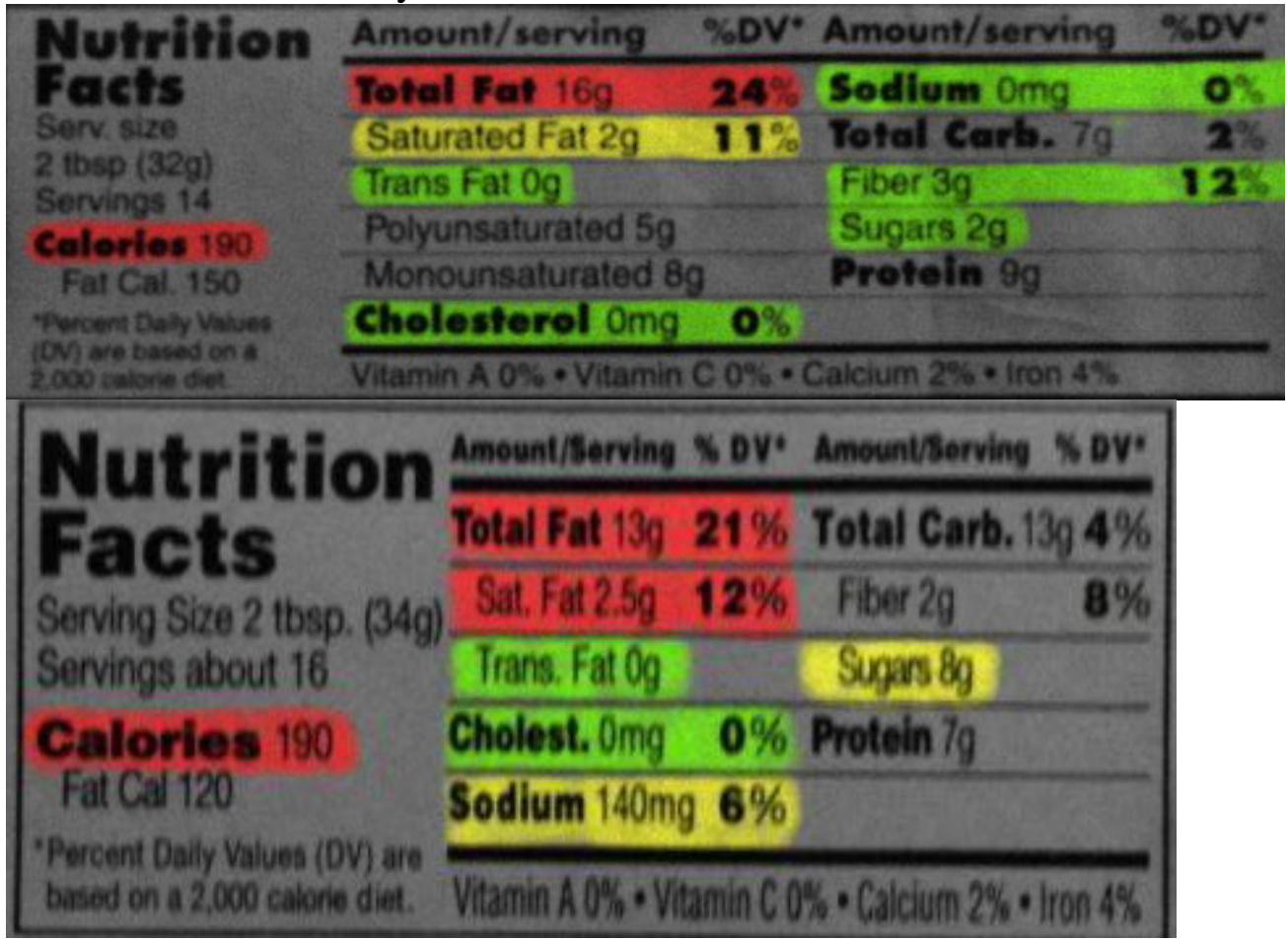

4. Frozen Dinner

Please choose the label you believe to be the healthiest

\begin{tabular}{|c|c|}
\hline \multirow[t]{2}{*}{$\begin{array}{l}\text { Nutrition Facts } \\
\text { Serving Size } 1 \text { Package (297g) } \\
\text { Servings Per Container } 1\end{array}$} & $\begin{array}{l}\text { Nutrition Facts } \\
\text { Serving Size } 1 \text { Package }(297 \mathrm{~g}) \\
\text { Servings Per Container } 1\end{array}$ \\
\hline \multirow{2}{*}{\multicolumn{2}{|c|}{$\begin{array}{l}\text { Amount Per Serving } \\
\text { Calories } 320 \text { Calories from Fat } 70\end{array}$}} \\
\hline & \\
\hline \% Daily Value* & \multirow{2}{*}{$\begin{array}{r}\text { Calories } 340 \text { Calories from Fat } 110 \\
\% \text { Daily Value* }\end{array}$} \\
\hline Total Fat $8 \mathrm{~g} \quad 12 \%$ & \\
\hline Saturated Fat $4 \mathrm{~g}$ & Total Fat $12 \mathrm{~g} \quad 18 \%$ \\
\hline$\frac{\text { Trans Fat } 0 \mathrm{~g}}{\text { Polyunsaturated Fat } 0 \mathrm{~g}}$ & Saturated Fat $6 \mathrm{~g}$ \\
\hline Monounsaturated Fat $2 \mathrm{~g}$ & Trans Fat $0.5 \mathrm{~g}$ \\
\hline Cholesterol $30 \mathrm{mg}$ & Cholesterol $35 \mathrm{mg}$ \\
\hline Sodium $630 \mathrm{mg} \quad 26 \%$ & Sodium $850 \mathrm{mg} \quad 35 \%$ \\
\hline Potassium $710 \mathrm{mg} \quad \mathbf{2 0} \%$ & Total Carbohydrate $37 \mathrm{~g} 12 \%$ \\
\hline Total Carbohydrate $45 \mathrm{~g} \mathbf{1 5 \%}$ & Dietary Fiber $3 \mathrm{~g} \quad 11 \%$ \\
\hline Sugars $8 \mathrm{~g}$ & Sugars $8 \mathrm{~g}$ \\
\hline Protein $17 \mathrm{~g}$ & Protein $20 \mathrm{~g}$ \\
\hline
\end{tabular}


5. Juice

Please choose the label you believe to be the healthiest

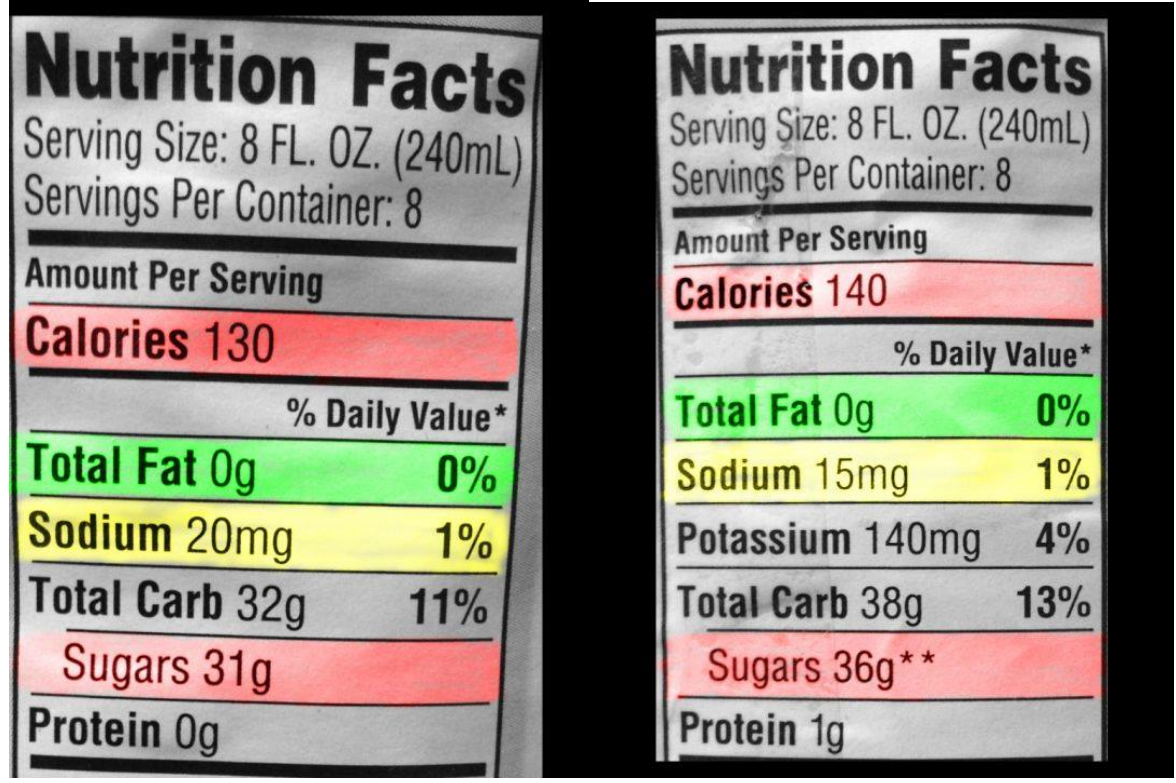

\section{Cereal}

Please choose the label you believe to be the healthiest

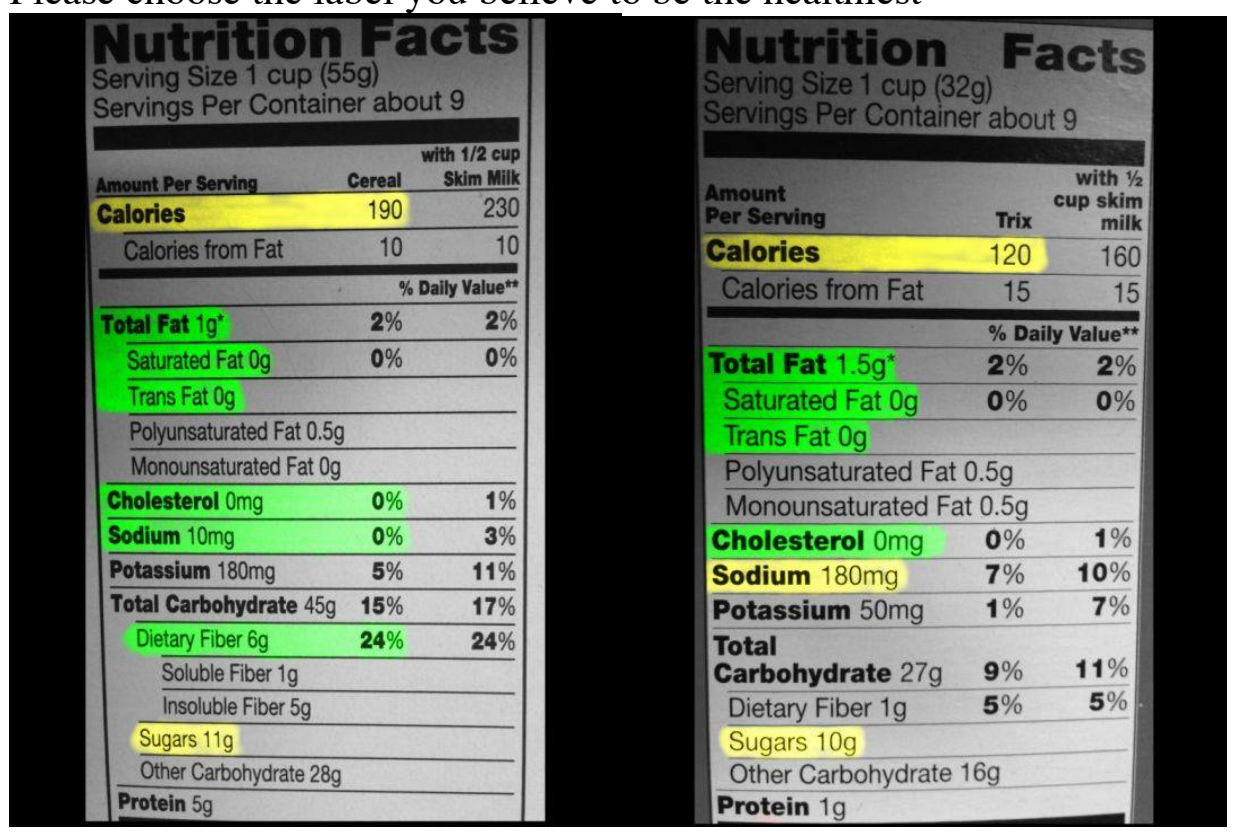




\section{Butter}

Please choose the label you believe to be the healthiest

\begin{tabular}{|c|c|c|c|c|}
\hline \multicolumn{2}{|c|}{\begin{tabular}{|l|} 
Nutriftion Facts \\
Serving Size 1 tbsp (14g) \\
Servings Per Container 32
\end{tabular}} & & & \\
\hline \multicolumn{5}{|c|}{ Amount Per Serving } \\
\hline \multicolumn{5}{|c|}{ \% Daily Value* } \\
\hline \multirow{2}{*}{\multicolumn{5}{|c|}{$\begin{array}{ll}\text { Total Fat } 11 \mathrm{~g} & \mathbf{1 7 \%} \\
\text { Saturated Fat } 7 \mathrm{~g} & \mathbf{3 7 \%}\end{array}$}} \\
\hline & $\mathbf{3 7} \%$ & & & \\
\hline \multicolumn{5}{|c|}{$\overline{T r a n s ~ F a t ~ O g}$} \\
\hline \multicolumn{2}{|l|}{ Cholesterol $30 \mathrm{mg}$} & \multicolumn{3}{|c|}{$\begin{array}{ll}\text { Sodium } 0 \mathrm{mg} & 0 \%\end{array}$} \\
\hline \multicolumn{5}{|c|}{ Total Carbohydrate 0g $\quad 0 \%$} \\
\hline \multicolumn{5}{|c|}{ Protein 0g } \\
\hline \multirow{5}{*}{$\begin{array}{l}\text { Mutrition } \\
\text { Facts } \\
\text { Sen: Sbe } 1 \text { Tosp (149) } \\
\text { Senings Per Conlainer } \\
\text { About is }\end{array}$} & kmountServing & sor & AmountServing & sor \\
\hline & Total Fat 109 & $15 \%$ & Cholest. 10mg & $3 \%$ \\
\hline & Sat Fat $3.5 \mathrm{~g}$ & $18 \%$ & Sodium $85 \mathrm{mg}$ & $4 \%$ \\
\hline & Trans Fat $0 \mathrm{~g}$ & & Total Carb. Og & $0 \%$ \\
\hline & Polyunsaturated Fat $2 g$ & & Protein $0 \mathrm{~g}$ & \\
\hline $\begin{array}{l}\text { Calories } 90 \\
\text { Fat Cal } 90\end{array}$ & Monounsaturated Fat $4 \mathrm{~g}$ & & & \\
\hline \multirow{2}{*}{ 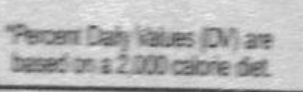 } & Vilamin A $8 \%$ & & & \\
\hline & Not a signilicart source of dietary fil & fors, sugh & 5, vianin C, calcium a & \\
\hline
\end{tabular}


8. Bread

Please choose the label you believe to be the healthiest

\begin{tabular}{|c|c|}
\hline $\begin{array}{l}\text { Butlth } \\
\text { Serving Size } 2 \text { Slices }(41 \mathrm{~g}) \\
\text { Servings Per Container } 11\end{array}$ & $\begin{array}{l}\text { Serving Size } 2 \text { slices }(43 \mathrm{~g}) \\
\text { Servings Per Container about } 13 \\
\text { Amount Per Serving }\end{array}$ \\
\hline Amount Per Serving \%DV 2 Slice 1 Slice & Calories 120 Calories from Fat 10 \\
\hline Calories 70 Calories from Fat 5 & \% Daily Value* \\
\hline Calories 35 Calories from Fat 0 & Total Fat $1 \mathrm{~g}$ \\
\hline \% Daily Value & Saturated Fat $0 \mathrm{~g}$ \\
\hline $\begin{array}{lll}\text { Total Fat } 0 \mathrm{~g}, \mathrm{Og} & \mathbf{0} \% & \mathbf{0} \% \\
\text { Saturated Fot }\end{array}$ & Trans Fat $\mathrm{Og}$ \\
\hline $\begin{array}{ll}\text { Saturated Fat } 0 \mathrm{~g}, 0 \mathrm{~g} & \mathbf{0} \% \quad \mathbf{0} \% \\
\text { Trans Fat } 0 \mathrm{~g}, 0 \mathrm{~g} & \end{array}$ & Polyunsaturated Fat $0.5 \mathrm{~g}$ \\
\hline Polyunsaturated Fat $0 \mathrm{~g}, 0 \mathrm{~g}$ & Monounsaturated Fat Og \\
\hline Monounsaturated Fat $0 \mathrm{~g}, 0 \mathrm{~g}$ & Cholesterol Omg \\
\hline $\begin{array}{lll}\text { Cholesterol Omg,0mg } & \mathbf{0 \%} & \mathbf{0 \%} \\
\text { Sodium 150ma } 80 \mathrm{ma} & \mathbf{6 \%} & \mathbf{3} \%\end{array}$ & Sodium $230 \mathrm{mg}$ \\
\hline $\begin{array}{lll}\text { sodium 150mg,80mg } & \mathbf{6 \%} & \mathbf{3} \% \\
\text { Total Carbohydrate } 16 \mathrm{~g}, 8 \mathrm{~g} & \mathbf{5 \%} & \mathbf{3 \%}\end{array}$ & $\begin{array}{l}\text { Total Carbohydrate } 24 \mathrm{~g} \quad 8 \% \\
\end{array}$ \\
\hline Dietary Fiber $5 g, 3 g \quad 20 \% \quad 12 \%$ & Dietary Fiber less than $1 \mathrm{~g} \quad \mathbf{3} \%$ \\
\hline Sugars $2 \mathrm{~g}, 1 \mathrm{~g}$ & Sugars $3 g$ \\
\hline Protein $5 g, 2 g$ & Protein 4g \\
\hline
\end{tabular}


APPENDIX D

\section{DEMOGRAPHIC AND NUTRITION QUESTIONS}

\section{Demographic Questions}

1. What is your current Age?

(free response)

2. What is your gender?

-Male

-Female

-Other (free response)

3. What Ethnicity do You Most Closely Identify With?

-Asian

-White

-Hispanic

-Native American

-African American/Black

-Other (Free Response)

4. Please State Your Current Major

(free response)

5. Current Year in School:

-Freshman

-Sophomore

-Junior

-Senior

-Graduate Student

-Other (free response)

Nutrition Questions

1. On a scale of 1 to 5, 1 being Poor and 5 being Excellent, how would you rate your knowledge of nutrition?

1. Poor

2. Fair

3. Neutral 
4. Good

5. Excellent

2. How much nutrition education have you had?

-no nutrition classes

-1-2 nutrition classes

-more than two nutrition classes

3. One a scale of 1-5, 1 being Very Unimportant and 5 being Very Important, how important is eating healthy to you?

1. Very Unimportant

2. Unimportant

3. Neutral

4. Important

5. Very Important

4. On a scale of 1 to 5, 1 being Very Ineffective and 5 being Very Effective, how effective do you think you were at choosing the correct labels in this survey?

1. Very Ineffective

2. Ineffective

3. Neutral

4. Effective

5. Very Effective

5. On a scale of 1 to 5, 1 being Never and 5 being Always, how often do you look at nutrition labels?

1. Never

2. Infrequent

3. Sometimes

4. Often

5. Always

6. On a scale of 1 to 5, 1 being Poor and 5 being Excellent, how well you believe you interpret food labels?

1. Poor

2. Not Well

3. Fair

4. Good

5. Excellent

7. How do you currently feel about your weight

-Underweight

-Healthy

-Overweight 
8. On a scale of 1 to 5,1 being Very Unhealthy and 5 being Very Healthy, how would you rate your current health status?

1. Very Unhealthy

2. Unhealthy

3. Moderately Healthy

4. Healthy

5. Very Healthy 